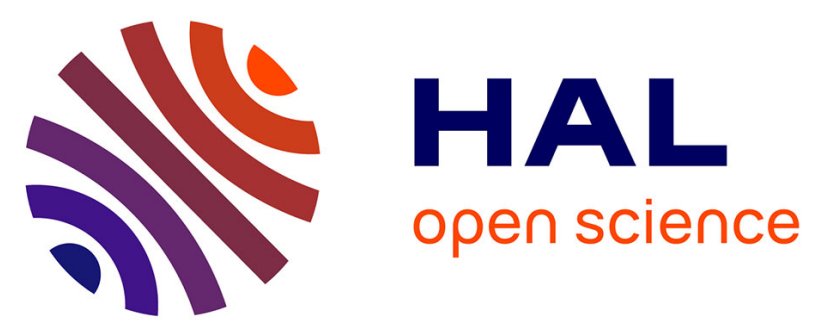

\title{
Chromium hazard and risk assessment: New insights from a detailed speciation study in a standard test medium.
}

Imad Aharchaou, Jean-Sébastien Py, Sébastien Cambier, Jean-Luc Loizeau, Geert Cornelis, Philippe Rousselle, Eric Battaglia, Davide Anselmo Luigi Vignati

\section{To cite this version:}

Imad Aharchaou, Jean-Sébastien Py, Sébastien Cambier, Jean-Luc Loizeau, Geert Cornelis, et al.. Chromium hazard and risk assessment: New insights from a detailed speciation study in a standard test medium.. Environmental Toxicology and Chemistry, 2017, 37 (4), pp.983 - 992. 10.1002/etc.4044 . hal-01906558

\section{HAL Id: hal-01906558 https://hal.science/hal-01906558}

Submitted on 26 Oct 2018

HAL is a multi-disciplinary open access archive for the deposit and dissemination of scientific research documents, whether they are published or not. The documents may come from teaching and research institutions in France or abroad, or from public or private research centers.
L'archive ouverte pluridisciplinaire HAL, est destinée au dépôt et à la diffusion de documents scientifiques de niveau recherche, publiés ou non, émanant des établissements d'enseignement et de recherche français ou étrangers, des laboratoires publics ou privés. 
This is the accepted version of the following article:

Aharchaou I, Py J-S, Cambier S, Loizeau J-L, Cornelis G, Rousselle P, Battaglia E, Vignati DAL. Chromium hazard and risk assessment: New insights from a detailed speciation study in a standard test medium. Environmental Toxicology and Chemistry, DOI: 10.1002/etc.4044

which has been published in final form at http://onlinelibrary.wiley.com/wol1/doi/10.1002/etc.4044/abstract.

This article may be used for non-commercial purposes in accordance with the Wiley SelfArchiving Policy https://authorservices.wiley.com/author-resources/JournalAuthors/licensing-open-access/open-access/self-archiving.html. 


\title{
CHROMIUM HAZARD AND RISK ASSESSMENT: NEW INSIGHTS FROM A DETAILED SPECIATION STUDY IN A STANDARD TEST MEDIUM
}

\author{
Imad Aharchaou ${ }^{\mathrm{a}}$, Jean-Sébastien Py ${ }^{\mathrm{b}}$, Sébastien Cambier ${ }^{\mathrm{c}}$, Jean-Luc Loizeau ${ }^{\mathrm{d}}$, Geert Cornelis ${ }^{\mathrm{e}}$, \\ Philippe Rousselle ${ }^{\mathrm{a}}$, Eric Battaglia ${ }^{\mathrm{a}}$, Davide A.L. Vignati ${ }^{\mathrm{a}^{*}}$ \\ ${ }^{a}$ Laboratoire Interdisciplinaire des Environnements Continentaux UMR 7360, Université de Lorraine \\ and CNRS, Metz, France \\ ${ }^{\mathrm{b}}$ Agence nationale de sécurité sanitaire de l'alimentation, de l'environnement et du travail, Laboratoire \\ de Nancy, Nancy, France \\ ${ }^{\mathrm{c}}$ Luxembourg Institute of Science and Technology, Esch sur Alzette, Luxembourg \\ ${ }^{\mathrm{d}}$ Department F.-A. Forel for Environmental and Aquatic Sciences and Institute for Environmental \\ Sciences, University of Geneva, Genève, Switzerland \\ ${ }^{\mathrm{e}}$ Swedish University of Agricultural Sciences, Department of Soil and Environment, Uppsala, Sweden
}

\begin{abstract}
Despite the consensus about the importance of chemical speciation in controlling the bioavailability and ecotoxicity of trace elements, detailed speciation studies during laboratory ecotoxicity testing remain scarce, contributing to uncertainty when extrapolating laboratory findings to real field situations in risk assessment. We characterized the speciation and ecotoxicological effects of $\mathrm{Cr}^{\mathrm{III}}$ and $\mathrm{Cr}^{\mathrm{VI}}$ in the OECD medium for algal ecotoxicity testing. Total and dissolved $(<0.22 \mu \mathrm{m}) \mathrm{Cr}$ concentrations showed little variability in media spiked with $\mathrm{Cr}^{\mathrm{VI}}$, while dissolved $\mathrm{Cr}$ concentration decreased by as much as $80 \%$ over 72 hours in medium amended with $\mathrm{Cr}^{\mathrm{III}}$. Analyses by ion chromatography ICP-MS highlighted the absence of redox interconversion between $\mathrm{Cr}^{\mathrm{III}}$ or $\mathrm{Cr}^{\mathrm{VI}}$ both in the presence and absence of algal cells (Raphidocelis subcapitata). Furthermore, the concentration of ionic $\mathrm{Cr}^{\mathrm{III}}$ dropped below detection limits in less than 2 hours with the corresponding formation of carbonate complexes and $\mathrm{Cr}$ hydroxides. Precipitation of $\mathrm{Cr}^{\mathrm{III}}$ in the form of colloidal particles of variable diameters was confirmed by nanoparticle tracking analysis, spICP-MS and single particle counting. In terms of time weighted dissolved $(<0.22 \mu \mathrm{m}) \mathrm{Cr}$ concentration, $\mathrm{Cr}^{\mathrm{III}}$ was 4 to 10 times more toxic than $\mathrm{Cr}^{\mathrm{VI}}$. However, $\mathrm{Cr}^{\mathrm{III}}$ ecotoxicity could arise from interactions between free ionic $\mathrm{Cr}^{\mathrm{III}}$ and algae at the beginning of the test, from the presence of $\mathrm{Cr}$-bearing nanoparticles or a combination of the two. Future ecotoxicological studies must pay more attention to $\mathrm{Cr}$ speciation to reliably compare the ecotoxicity of $\mathrm{Cr}^{\mathrm{III}}$ and $\mathrm{Cr}^{\mathrm{VI}}$.
\end{abstract}

\section{Keywords}

Trace metals, Chromium, Metal speciation, Algae, Hazard/Risk assessment 


\section{INTRODUCTION}

The bioavailability and ecotoxicity of trace elements in natural environments are determined by the complex interplay among the ecological traits of living organisms, the toxicodynamics and toxicokinetics of trace elements, and the elemental speciation in environmental matrices (Fairbrother et al. 2007; Mason 2013; Harris et al. 2014). Elemental speciation refers to various physico-chemical forms in which trace elements occur in a given environment and, in some cases, includes the presence of different oxidation states with contrasting environmental biogeochemistry. In the specific case of chromium, the importance of speciation is well appreciated with regard to its biogeochemical cycle (Masscheleyn et al. 1992; Dominik et al. 2007; Saputro et al. 2014) and biological effects (WHO 2009; WHO 2013). In surface waters, chromium mainly occurs in two oxidation states, namely $\mathrm{Cr}^{\mathrm{VI}}$ and $\mathrm{Cr}^{\mathrm{III}}$, with contrasting environmental and biological behavior. Hexavalent chromium, a recognized human carcinogen, forms negatively charged chemical species, interacts little with colloidal and particulate material, has a high environmental mobility, and easily crosses biological membranes (WHO 2013). In contrast, $\mathrm{Cr}^{\mathrm{III}}$ preferentially forms positively charged chemical species, tends to associate with colloids or suspended particulate matter and is considered of less ecotoxicological concern (WHO 2009; WHO 2013). In most environmental settings, both redox forms occur simultaneously, albeit in variable proportions (Bobrowski et al. 2004; Saputro et al. 2014) and interconversions between them have been documented along with the corresponding controlling factors (Rai et al. 1989; Richard and Bourg 1991; Lin 2002). However, experimental research on $\mathrm{Cr}$ speciation in standardized ecotoxicological test media has received limited attention. Thermodynamic speciation calculations are increasingly used to predict the $\mathrm{Cr}$ forms likely to exist in ecotoxicological exposure media, thus aiding experimental planning and data interpretation (Dazy et al. 2008; Didur et al. 2013; Liu et al. 2015). These calculations also suggest that insoluble species of $\mathrm{Cr}^{\mathrm{III}}$ (mostly Cr oxyhydroxides) can form in ecotoxicological test media for algae, daphnids and aquatic plants (Dazy et al. 2008; Vignati et al. 2010; Ponti et al. 2014). The presence of such chemical species can modify the fraction of $\mathrm{Cr}^{\mathrm{III}}$ that is potentially bioavailable for the test organisms during the exposure period, because in most cases it is assumed that the bio-availability of metals is related to the free ion activity (Morel, 1983). Insoluble species also explain the often large differences between total and total filterable $(<0.45 \mu \mathrm{m}) \mathrm{Cr}$ concentrations found in test media spiked with $\mathrm{Cr}^{\mathrm{III}}$, the extent depending on medium composition (Chapman et al. 1980; Vignati et al. 2008; Ponti et al. 2014). It should also be noted that filterable $(<0.45 \mu \mathrm{m}) \mathrm{Cr}$ concentrations do not equal the sum of concentrations of truly dissolved $\mathrm{Cr}$ species, because the initial formation of precipitates may result in solids having particle sizes below this size cut-off. Furthermore, certain studies present results supporting the conclusion that $\mathrm{Cr}^{\mathrm{III}}$ is more ecotoxic than $\mathrm{Cr}^{\mathrm{VI}}$ (Holdway 1988; Thompson et al. 2002; Vignati et al. 2010; LiraSilva et al. 2011; Kováčik et al. 2015); in contrast with the current consensus considering $\mathrm{Cr}^{\mathrm{VI}}$ as the most ecotoxic redox form (WHO 2013). A more detailed understanding of $\mathrm{Cr}$ speciation in (standardized) laboratory test media used for ecotoxicity testing will help to both reconcile contrasting ecotoxicological results in controlled settings and improve our ability to extrapolate laboratory results to real-field risk assessment situations.

On the basis of the above considerations, three aspects related to $\mathrm{Cr}$ speciation, and its changes during a given (standardized) test, appear of particular importance for an improved understanding of the relative ecotoxicity of $\mathrm{Cr}^{\mathrm{III}}$ and $\mathrm{Cr}^{\mathrm{VI}}$ : a) the stability of (filterable) $\mathrm{Cr}$ concentrations added to the test medium, $b$ ) the possibility of redox interconversions between $\mathrm{Cr}^{\mathrm{III}}$ and $\mathrm{Cr}^{\mathrm{VI}}$, and c) the formation of $\mathrm{Cr}$ oxyhydroxides (i.e., Cr-bearing nanoparticles). In the present study, the ecotoxicity of three $\mathrm{Cr}^{\mathrm{III}}$ salts and one $\mathrm{Cr}^{\mathrm{VI}}$ salt commonly used in ecotoxicological studies was investigated using the standard algal medium ISO 8692 (OECD 2011), hereinafter test medium, as exposure matrix and the green alga Raphidocelis 
subcapitata as test organism. The behavior and speciation of both $\mathrm{Cr}^{\mathrm{III}}$ and $\mathrm{Cr}^{\mathrm{VI}}$ forms, including their possible interconversions, were investigated in detail over $72 \mathrm{~h}$; corresponding to the typical duration of a standard algal test (OECD 2011). Our results showed rapid changes (i.e., within hours) in $\mathrm{Cr}^{\mathrm{III}}$ speciation which calls for a thorough reconsideration of the current knowledge about the relative ecotoxicity of $\mathrm{Cr}^{\mathrm{III}}$ and $\mathrm{Cr}^{\mathrm{VI}}$ in terms of both hazard and risk assessment.

\section{MATERIALS AND METHODS}

\section{Chemicals}

All chemicals used were of highest purity. For the various experiments, the test medium ISO8692 was prepared as described in OECD guideline 201 (OECD 2011) and spiked with either $\mathrm{Cr}^{\mathrm{VI}}$ as potassium dichromate $\left(\mathrm{K}_{2} \mathrm{Cr}_{2} \mathrm{O}_{7}\right.$, VWR, purity $99.8 \%$ min, CAS number 7778 50-9) or with one of the following $\mathrm{Cr}^{\mathrm{III}}$ salts: chromium chloride $\left(\mathrm{CrCl}_{3} \cdot 6 \mathrm{H}_{2} \mathrm{O}\right.$; Alfa Aesar, 99.5\% min, Crystalline, CAS number 10060-12-5), chromium potassium sulfate $\left(\mathrm{KCr}\left(\mathrm{SO}_{4}\right)_{2} \cdot 12 \mathrm{H}_{2} \mathrm{O}\right.$; VWR, 99\%, CAS number 7788-99-0) or chromium nitrate $\left(\mathrm{Cr}\left(\mathrm{NO}_{3}\right)_{3} \cdot 9 \mathrm{H}_{2} \mathrm{O}\right.$; Alfa Aesar, 98.5\%, Crystalline, CAS number 7789-02-8).

All filtrations were performed using $0.22 \mu \mathrm{m}$ syringe filters (Millex $33 \mathrm{~mm}$ diameter, PVDF, Millipore, reference number SLGV033NB) prewashed one time with $10 \mathrm{~mL}$ of diluted (10\% v/v) hydrochloric acid (HCl Suprapur 30\%, Merck Millipore, lot number Z0309518344) and three times with $10 \mathrm{~mL}$ of ultrapure water (Millipore, Q-POD®). A preliminary experiment showed that Millex syringe filters with nominal pore sizes of 0.22 and $0.45 \mu \mathrm{m}$ yielded comparable results for aliquots of test medium amended with $60 \mu \mathrm{g} \mathrm{Cr}{ }^{\text {III }} / \mathrm{L}$ (data not shown). All samples for the analysis of total $\mathrm{Cr}$ concentration were acidified at $1 \% \mathrm{v} / \mathrm{v}$ with concentrated nitric acid $\left(\mathrm{HNO}_{3} 67 \%\right.$, Prolabo, VWR, batch number 1108110). A solution of $0.4 \mathrm{M}$ nitric acid (Chemlab, suprapur 70\%, batch: 221831609 ) spiked with $1 \mu \mathrm{g} / \mathrm{L}$ of rhodium was used as internal standard during the analyses of $\mathrm{Cr}$ speciation.

\section{Chromium ecotoxicity}

The ecotoxicity of $\mathrm{Cr}^{\mathrm{VI}}$ and $\mathrm{Cr}^{\mathrm{III}}$ salts to the green alga Raphidocelis subcapitata (strain 278/4 originally obtained from the Culture Collection of Algae and Protozoa - CCAP - Argyll, Scotland, United Kingdom; formerly known as Pseudokirchneriella subcapitata) was evaluated according to OECD guideline 201 (OECD 2011). Tests were performed as previously described (Vignati et al. 2010) using inoculums of 20,000 cells $/ \mathrm{mL}$ and nominal exposure concentrations of 9, 18, 35, 70, 140, 280, 560, 1125, $2250 \mu \mathrm{g} \mathrm{Cr} / \mathrm{L}$. The effects of $\mathrm{Cr}$ salts on algal growth were expressed as the effective exposure concentrations (ECs50) that produced a 50\% decrease in algal fluorescence (BMG LabTechnologies, Fluostar), considered as a proxy for algal biomass. The ECs50 were calculated by performing a nonlinear regression on Hill's model with the macro REGTOX (Version EV7.0.4., E. Vindimian) (Vindimian 2010). In the case of $\mathrm{Cr}^{\mathrm{III}}$, ECs50 were estimated based on both nominal concentrations and Time-Weighted Mean (TWM) dissolved measured concentrations (OECD 2012). Starting from this point, the terms total and dissolved concentrations will indicate the unfiltered and filtered $(0.22 \mu \mathrm{m})$ portions of measured $\mathrm{Cr}$ levels.

\section{Temporal evolution of $\mathrm{Cr}$ concentration in the test medium}

Aliquots $(50 \mathrm{~mL})$ of freshly prepared test medium were transferred to acid-washed Erlenmeyer flasks $(150 \mathrm{~mL})$ and spiked with a $\mathrm{Cr}$ concentration corresponding to the ECs50 of either $\mathrm{Cr}^{\mathrm{III}}$ (added as $\mathrm{CrCl}_{3} \cdot 6 \mathrm{H}_{2} \mathrm{O}$ ) or $\mathrm{Cr}^{\mathrm{VI}}$ (added as $\mathrm{K}_{2} \mathrm{Cr}_{2} \mathrm{O}_{7}$ ) in the presence or absence of an initial algal inoculum of 20,000 cells $/ \mathrm{mL}$. Aliquots were analyzed for total and dissolved $\mathrm{Cr}$ after $0.5,1,2,4,8,24,48$, and $72 \mathrm{~h}$ of incubation under continuous light $(90-110$ $\left.\mu \mathrm{E} / \mathrm{m}^{2} / \mathrm{s}\right)$ at $21 \pm 2{ }^{\circ} \mathrm{C}$ and, for biotic samples only, rotary agitation (100 rpm). For dissolved 
$\mathrm{Cr}$ determination, the first $5 \mathrm{~mL}$ of filtered solution were used for preconditioning the filters and discarded. Preconditioning aimed at removing possible residues of ultrapure water from filter pores and saturate possible sorption sites for $\mathrm{Cr}$. Total and dissolved $\mathrm{Cr}$ concentrations were determined by flame atomic absorption spectrometry (FAAS, Perkin-Elmer AAnalyst 100 ) or, for concentrations $<20 \mu \mathrm{g} / \mathrm{L}$, graphite furnace atomic absorption spectrometry (GFAAS, Varian spectra 300, using $0.1 \% \mathrm{Mg}\left(\mathrm{NO}_{3}\right)_{2}$ as matrix modifier according to manufacturer instructions). Quantification limits were $10 \mu \mathrm{g} / \mathrm{L}$ for FAAS and $0.2 \mu \mathrm{g} / \mathrm{L}$ for GFAAS. Certified reference materials SPS-SW1 $(2.00 \pm 0.02 \mu \mathrm{g} / \mathrm{L})$ and WW1 $(200 \pm 1$ $\mu \mathrm{g} / \mathrm{L}$ ), both from SpectraPure standards (Manglerud, Norway), were used as quality controls. All analytical results are expressed in $\mu \mathrm{g} \mathrm{Cr} / \mathrm{L}$.

The statistical significance of the temporal changes in $\mathrm{Cr}$ concentrations was evaluated by one-way ANOVA with Tukey post-hoc comparison. Visual Minteq modelling (ver 3.1) was done to investigate $\mathrm{Cr}^{\mathrm{III}}$ speciation in test medium amended with an initial total concentration of $60 \mu \mathrm{g} \mathrm{Cr} / \mathrm{L}$. No redox transformations were assumed, because it will be argued based on experimental proof that these did not occur. Calculations were performed using experimentally measured $\mathrm{Cr}$ concentrations and $\mathrm{pH}$ values, and the test medium composition as reported in OECD (2011). No modifications were made to the Visual Minteq default database and the Debye-Hückel equation was used for activity corrections.

\section{Chromium redox speciation}

To investigate $\mathrm{Cr}$ redox speciation and the possible interconversion between $\mathrm{Cr}^{\mathrm{III}}$ and $\mathrm{Cr}^{\mathrm{VI}}$, aliquots $(50 \mathrm{~mL})$ of the test medium were spiked with either $\mathrm{Cr}^{\mathrm{VI}}$ or $\mathrm{Cr}^{\mathrm{III}}$ (added as chloride) both in absence (abiotic medium) and presence (biotic medium) of algal inoculums (20,000 cells $/ \mathrm{mL}$ ). Nominal $\mathrm{Cr}$ concentrations in the spiked solutions were $60 \mu \mathrm{g} / \mathrm{L}$ for $\mathrm{Cr}^{\mathrm{III}}$ and 115 $\mu \mathrm{g} / \mathrm{L}$ for $\mathrm{Cr}^{\mathrm{VI}}$, corresponding to the calculated $72 \mathrm{~h}$ ECs50 (see section Chromium ecotoxicity in Results and discussion). Samples were analyzed immediately after spiking $(\mathrm{t}=0)$ or incubated at $23 \pm 1{ }^{\circ} \mathrm{C}$, under continuous light $\left(90-110 \mu \mathrm{E} / \mathrm{m}^{2} / \mathrm{s}\right)$ and, for biotic samples only, rotary agitation (100 rpm) for 24,48 and $72 \mathrm{~h}$ prior to analysis (Figure S1). At the end of each incubation period, sample aliquots for $\mathrm{Cr}$ speciation were filtered as described above. After preconditioning the filters with $5 \mathrm{~mL}$ (subsequently discarded) of Cr-amended test medium, $10 \mathrm{~mL}$ of filtrate was collected in polystyrene sample vials and immediately analyzed by ion chromatography-inductively coupled plasma mass spectrometry (IC-ICPMS). Samples were kept at between 4 and $6{ }^{\circ} \mathrm{C}$ in a refrigerated sample tray during analysis. An additional abiotic sample of test medium (2 L) was prepared in an acid-washed lowdensity polyethylene bottle and spiked with $60 \mu \mathrm{g} / \mathrm{L}$ of $\mathrm{Cr}^{\mathrm{II}}$ to follow more closely the kinetics of the changes in $\mathrm{Cr}^{\mathrm{III}}$ speciation (Sacher et al. 1999; Séby et al. 2003). Aliquots for analysis were recovered every 20 min over the first 6 hours after spiking and again after 24 , 48 , and 72 hours of incubation in the same conditions described above.

Trivalent $\mathrm{Cr}$ and hexavalent $\mathrm{Cr}$ species were separated and quantified by IC-ICP-MS using a Thermo ICS 5000+ pump coupled with an anion exchange column (Thermo AG7 2x50 mm) and connected to the nebulizer of an ICP-MS (Thermo, Series XII) (Table S1). A solution of $0.4 \mathrm{M}$ nitric acid spiked with $1 \mu \mathrm{g} / \mathrm{L}$ of rhodium was used to elute the $\mathrm{Cr}$ species from the anion exchange column (see Table $\mathrm{S} 1$ for more details). The analyses were carried out according to the method developed by the French Agency for Food, Environmental \& Occupational Health \& Safety (ANSES) on the basis of the application note from the supplier (Sacher et al. 1999; ANSES/LHN/MT-CrVI). Chromium detection was performed at m/z 52 and 53. Experimental IC-ICP-MS results were compared with those of speciation modeling carried out as described previously (section Temporal evolution of $\mathrm{Cr}$ concentration) using Visual Minteq. 
Formation of $\mathrm{Cr}$ nanoparticles in the test medium

Aliquots of test medium were spiked with $60 \mu \mathrm{g} / \mathrm{L}$ of $\mathrm{Cr}^{\mathrm{III}}$ (added as chloride or nitrate) and the formation of Cr-containing particles was investigated by Nanoparticle Tracking Analysis (NTA), spICP-MS (single particle ICP-MS) and Single Particle Counting (SPC) over $72 \mathrm{~h}$; that is the typical duration of an algal ecotoxicological test. Blank samples consisting of unspiked test medium were systematically analyzed along with the corresponding samples. Total and dissolved $\mathrm{Cr}$ concentrations were determined by FAAS during the various experiments.

For NTA (Nanosight NS500; Malvern instruments Ltd, UK), spiked samples were aged for 0, $0.5,1,2,24,48$, and $72 \mathrm{~h}$ and assayed (before and after filtration) for particle concentration and particle size distribution (PSD). The NS500 provides detailed analysis of the concentration and size distribution of all types of nanoparticles from $10 \mathrm{~nm}$ to $1000 \mathrm{~nm}$ in diameter (Carr and Wright 2013) using the properties of both light scattering and Brownian motion in liquid suspensions. Particles in suspension in the sample chamber (volume $=0.3$ $\mathrm{mL}$ ) were visualized using a 20x magnification microscope equipped with a camera operated at 25 frames per second for $60 \mathrm{~s}$. The resulting video files were elaborated using the built-in software (NTA 2.3 build 0033) to calculate the hydrodynamic diameter of the individually tracked particles. After each measurement, the sample chamber was flushed with milliQ water and reloaded with the next sample aliquot. All measurements were done in triplicate and the mean ( \pm one standard deviation) of particle concentration and average size calculated (see supplementary information for protocol optimization).

While NTA determines the total particle count, spICP-MS (Perkin Elmer NexION 350D ICPMS) was used to specifically measure Cr-containing particles. Samples were aged for 0, 24, 48 and $72 \mathrm{~h}$ and diluted to a theoretical concentration of $0.06 \mu \mathrm{g} / \mathrm{L}$ total $\mathrm{Cr}$ before analysis. The transport efficiency was calculated based on a dissolved standard curve of Au stabilized by $0.1 \%$ cysteine and on the TEM-based median size $(56 \mathrm{~nm})$ of gold nanoparticles (NIST8013, nominal diameter $60 \mathrm{~nm}$ ) using the method of Pace et al. (2011). Data acquisition was performed in fast acquisition scanning technique (FAST) mode with a dwell time of 50 $\mu$ s over $100 \mathrm{~s}$. Raw data (two million readings per sample) were extracted and loaded into the Nanocount software (http://blogg.slu.se/nanocount/) for the determination of particle number and particle size distribution. Correction for dissolved concentrations was performed using outlier analysis based on a $5 \times \sigma$ criterion specifically developed for FAST data (Tuoriniemi et al. 2015). Peak integration time was set to $20 \mathrm{~ms}$ and the minimum detectable cluster was set at 4 ions. Distributions of the corresponding spherical size were calculated assuming a $\mathrm{Cr}(\mathrm{OH})_{3}\left(\rho=3.11 \mathrm{~g} / \mathrm{cm}^{3}\right)$ composition and a spherical shape. It should be noted that these were assumptions as the exact composition and shape of the formed particles are unknown. However, considering the measured $\mathrm{pH}$ range of the test medium initially spiked with $60 \mu \mathrm{g}$ $\mathrm{Cr} / \mathrm{L}$ (7.8-7.9 units), trivalent chromium is expected to rapidly undergo hydrolysis and form amorphous oxyhydroxides (Rai et al. 1989; Kotaś and Stasicka 2000). The assumption on particle shape would allow comparison with the results obtained using other methods. To detect the presence of particles outside the NTA and spICP-MS measuring range, samples were analyzed after $0,24,48$, and 72 hours of incubation using three Single Particle Counters (SPCs): a high sensitivity in-situ monitor (HSLIS) Model M50 for the range 50 to $200 \mathrm{~nm}$ and two Volumetric Spectrometers (LiQuilaz-S02 and LiQuilaz-S05, Particle Measuring Systems, Boulder, CO, U.S.A) for the ranges 200 to $2000 \mathrm{~nm}$ and $500 \mathrm{~nm}$ to $20 \mu \mathrm{m}$, respectively. The SPCs use light scattering to count individual particles across 31 size classes with some overlapping between the LiQuilaz-S02 and S05 (Rossé and Loizeau 2003). Results for spiked medium were corrected for blank values. 


\section{RESULTS AND DISCUSSION}

\section{Chromium ecotoxicity and temporal evolution of $\mathrm{Cr}$ concentrations}

Results of ecotoxicity tests were highly reproducible with ECs50 at $72 \mathrm{~h}$ (mean value \pm one standard deviation) of $113 \pm 3 \mu \mathrm{g} / \mathrm{L}(\mathrm{n}=3)$ for $\mathrm{K}_{2} \mathrm{Cr}_{2} \mathrm{O}_{7}, 59 \pm 3 \mu \mathrm{g} / \mathrm{L}$ for $\mathrm{CrCl}_{3} \cdot 6 \mathrm{H}_{2} \mathrm{O}(\mathrm{n}=6)$, $61 \pm 8 \mu \mathrm{g} / \mathrm{L}$ for $\mathrm{Cr}\left(\mathrm{NO}_{3}\right)_{3} \cdot 9 \mathrm{H}_{2} \mathrm{O}(\mathrm{n}=3)$ and $62 \pm 3 \mu \mathrm{g} / \mathrm{L}$ for $\mathrm{KCr}\left(\mathrm{SO}_{4}\right)_{2} \cdot 12 \mathrm{H}_{2} \mathrm{O}(\mathrm{n}=3)$. The ECs50 values reported in the literature for freshwater algae range from 130 to $470 \mu \mathrm{g} / \mathrm{L}$ for $\mathrm{Cr}^{\mathrm{VI}}$ and from $30 \mu \mathrm{g} / \mathrm{L}$ to over $1000 \mu \mathrm{g} / \mathrm{L}$ for $\mathrm{Cr}^{\mathrm{III}}$ (WHO 2009; Vignati et al. 2010; OECD 2011; WHO 2013). In the case of $\mathrm{Cr}^{\mathrm{VI}}$, a ring test involving 16 laboratories determined a range of $72 \mathrm{~h}-\mathrm{ECs} 50$ between 70 and $260 \mu \mathrm{g} \mathrm{Cr} / \mathrm{L}$ for Scenedesmus subspicatus and Selenastrum capricornutum (a former name for $R$. subcapitata) based on algal biomass endpoint (Munn et al. 2005; WHO 2013); which agrees with our results. In the case of $\mathrm{Cr}^{\mathrm{III}}$, our results are in the low range of the values reported in the literature and indicate a higher toxicity of $\mathrm{Cr}^{\mathrm{III}}$ compared with $\mathrm{Cr}^{\mathrm{VI}}$; an occurrence also reported in previous research (Holdway 1988; Thompson et al. 2002; Vignati et al. 2010; Lira-Silva et al. 2011; Kováćik et al. 2015). Further insights in the relative ecotoxicity of the two redox forms of $\mathrm{Cr}$ can be gained by examining their behavior in the test medium. In particular, the detailed examination of $\mathrm{Cr}^{\mathrm{VI}}$ and $\mathrm{Cr}^{\mathrm{III}}$ behavior added to the test medium at concentrations corresponding to their respective ECs50 allows to exactly determine the actual concentrations responsible for the observed effects. At $\mathrm{t}=0 \mathrm{~h}$, the measured total and dissolved $\mathrm{Cr}$ concentrations (added as $\mathrm{Cr}^{\mathrm{III}}$ ) were similar and corresponded to the expected nominal values in both abiotic and biotic media. In the absence of algae, total $\mathrm{Cr}$ concentrations remained within $20 \%$ of the initial value over the first 24 hours and had decreased by about $40 \%$ after $72 \mathrm{~h}$. In the same experiment, dissolved $\mathrm{Cr}$ concentrations remained within $20 \%$ of the initial values only over the first two hours, but had dropped by $40 \%$ eight hours after spiking and by $83 \%$ after $72 \mathrm{~h}$ (Figure 1). The decrease in total $\mathrm{Cr}$ concentrations indicates that some of the added $\mathrm{Cr}$ may be lost to the walls of the test vessel over time. However, comparison of total and dissolved concentrations indicates that ca. 50\% of the added Cr likely occurs in the form of colloidal or particulate form (most likely amorphous $\mathrm{Cr}$ oxyhydroxides) starting from 24 hours after spiking (i.e., for over $2 / 3$ of the test duration). Calculations in Visual Minteq for an initial concentration of $60 \mu \mathrm{g} / \mathrm{L}$ as $\mathrm{Cr}^{\mathrm{III}}$ predicted that, in the observed $\mathrm{pH}$ range of 7.8 to 7.9 , the $\mathrm{Cr}(\mathrm{OH})_{3}$ species should account for $92-94 \%$ of the total Cr. Furthermore, about $80 \%$ of the initially added $\mathrm{Cr}^{\mathrm{III}}$ was predicted to precipitate in the form of amorphous $\mathrm{Cr}(\mathrm{OH})_{3}$, in very good agreement with the $80 \%$ decrease of the corresponding dissolved $\mathrm{Cr}$ concentration over 72h (Figure 1). Colloid/nanoparticle formation was indeed confirmed using NTA and spICP-MS (see section Formation of Cr nanoparticles in Results and Discussion). Analogous calculations using the dissolved $\mathrm{Cr}$ concentration measured at $72 \mathrm{~h}(11 \pm 0.25 \mu \mathrm{g} / \mathrm{Cr} \mathrm{L}, \mathrm{n}=3)$ also predicted that $\mathrm{Cr}(\mathrm{OH})_{3}$ would account for over $90 \%$ of the measured $\mathrm{Cr}$ concentration, but with less than $2 \%$ occurring in the precipitated phase. In both cases, the sum of the positively charged species $\mathrm{Cr}(\mathrm{OH})_{2}{ }^{+}$and $\mathrm{CrOH}^{2+}$ was predicted to represent about $3.5 \%$ of the total dissolved $\mathrm{Cr}$ and EDTA complexes were about $2.5 \%$. Further comparison between speciation calculations and analytical results is presented in the next section.

The difference between total and dissolved $\mathrm{Cr}$ concentrations becomes statistically significant starting from $8 \mathrm{~h}$ after spiking (one-way Anova with Tukey post-hoc comparison, $\mathrm{p}<0.01$ ). Considering the temporal decrease of the dissolved $\mathrm{Cr}$ concentration, assumed as a better proxy of the Cr potentially available to the algae (see de Paiva Magalhães et al. 2015 and references therein for a detailed discussion), the time-weighed mean (TMW) (OECD 2012) exposure concentration of the algae to $\mathrm{Cr}$ (added as $\mathrm{Cr}^{\mathrm{III}}$ ) was about $25 \mu \mathrm{g} / \mathrm{L}$ for an initial addition of $60 \mu \mathrm{g} / \mathrm{L}$ as $\mathrm{Cr}^{\mathrm{III}}$. Similar behavior of total and dissolved $\mathrm{Cr}$ concentration was observed over the concentration range $20-7,000 \mu \mathrm{g} / \mathrm{L}$ for $\mathrm{CrCl}_{3}$ and for selected 
concentrations of $\mathrm{Cr}\left(\mathrm{NO}_{3}\right)_{3}$ and $\mathrm{CrKSO}_{4}$ (Figures S2-S4); confirming that the decrease in the dissolved exposure concentrations must be considered and quantified when testing $\mathrm{Cr}^{\text {III }}$ toxicity in standardized laboratory media. These observations corroborate previous findings obtained by measuring the decrease in $\mathrm{Cr}$ concentrations in test medium directly in 96-well microplates in the absence of algae and without actually providing information on the total vs. dissolved Cr concentrations (Vignati et al. 2008; Vignati et al. 2010). In the presence of algae, both total and dissolved $\mathrm{Cr}$ concentrations decreased with time (Figure 1) and the decrease was more marked for the dissolved concentrations (over 95\% after 72 hours). The incomplete recovery of total $\mathrm{Cr}$ was likely caused by attachment of algal cells to the vessel's walls despite the constant agitation. Most importantly, the differences between dissolved $\mathrm{Cr}$ concentrations in the absence and presence of algae became statistically significant starting from $24 \mathrm{~h}$ after spiking (one-way Anova with Tukey post-hoc comparison, $\mathrm{p}<0.01$ ), indicating adsorption onto or absorption into the algal cells of most of the available dissolved $\mathrm{Cr}$. Based on the dissolved $\mathrm{Cr}$ concentrations in the presence of algae, the $72 \mathrm{~h}$ TMW effect concentration (EC50) for algal growth (in terms of biomass) was $11.5 \mu \mathrm{g} / \mathrm{L}$. Analogous experiments performed with aliquots of test medium amended with $\mathrm{Cr}^{\mathrm{VI}}$ at the corresponding EC50 concentration $(115 \mu \mathrm{g} / \mathrm{L})$ did not show significant changes in total or dissolved $\mathrm{Cr}$ concentration neither in the absence nor in the presence of algae (Figure S5). The above observations lead us to the conclusion that $\mathrm{Cr}^{\mathrm{III}}$ is 4 to 10 times more toxic than $\mathrm{Cr}^{\mathrm{VI}}$ when the $72 \mathrm{~h} \mathrm{EC} 50$ for $\mathrm{Cr}^{\mathrm{III}}$ is expressed as the TWM dissolved concentration estimated from measurements in the absence or presence of algae, respectively. However, the presence of algae had no measurable effect on dissolved $\mathrm{Cr}^{\mathrm{VI}}$ concentrations (Figure S6). One possibility is that the entrance of minimal quantities of $\mathrm{Cr}^{\mathrm{VI}}$ into the cells may suffice to reduce algal biomass, which would support the current consensus that $\mathrm{Cr}^{\mathrm{VI}}$ is more toxic than $\mathrm{Cr}^{\mathrm{III}}$. On the other hand, exposure to $\mathrm{Cr}^{\mathrm{VI}}$ has been shown to cause lysis of $R$. subcapitata cells at concentrations of $1.75 \mathrm{mg} / \mathrm{L}$ or higher added to an algal inoculum of $2 \times 10^{5}$ cells $/ \mathrm{mL}$ (Labra et al. 2007); which corresponds to an initial quantity of $8.75 \mathrm{ng}$ of $\mathrm{Cr}^{\mathrm{VI}}$ per algal cell at the beginning of the experiment (our calculation). This figure compares favorably with the value of $5.75 \mathrm{ng}$ of $\mathrm{Cr}^{\mathrm{VI}}$ per algal cell in our experimental conditions for an initial spike of $115 \mu \mathrm{g} / \mathrm{L}$. Upon cell lysis, the initially internalized $\mathrm{Cr}^{\mathrm{VI}}$ would be released back to the test medium resulting in an apparent stable total (dissolved) $\mathrm{Cr}$ concentration over the duration of the experiment. Note that $\mathrm{Cr}^{\mathrm{VI}}$ can undergo intracellular reduction to $\mathrm{Cr}^{\mathrm{III}}$ (Cheung and $\mathrm{Gu}$ 2007; Volland et al. 2012; Kováčik et al. 2015) which could also be released back to the test medium upon cell lysis; possibly in association with intracellular constituents preventing its precipitation in the test medium. While no experiments were performed to determine if cell lysis had occurred, we verified possible changes in the redox state of $\mathrm{Cr}$ in the test medium over the exposure duration.

\section{Chromium redox speciation}

Aliquots of test medium spiked with $\mathrm{Cr}^{\mathrm{VI}}$ exhibited a single peak, corresponding to the one observed in a standard solution of $\mathrm{Cr}^{\mathrm{VI}}$, with a retention time of about 50 s regardless of the presence of algae and of the incubation time (Figures $2 \mathrm{~A}$ and $\mathrm{S} 6$ ). The total $\mathrm{Cr}^{\mathrm{VI}}$ concentration, determined from total peak area, was $118 \mu \mathrm{g} / \mathrm{L}$ at $\mathrm{t}=0$ and $120 \mu \mathrm{g} / \mathrm{L}$ after $72 \mathrm{~h}$ of incubation in the abiotic test medium and $137 \mu \mathrm{g} / \mathrm{L}$ at $\mathrm{t}=0$ and $120 \mu \mathrm{g} / \mathrm{L}$ after $72 \mathrm{~h}$ in the biotic medium. No peaks corresponding to $\mathrm{Cr}^{\mathrm{III}}$ were observed in either abiotic or biotic test medium (Figures $2 \mathrm{~A}$ and S6). While this result does not provide information on possible $\mathrm{Cr}^{\mathrm{VI}}$ to $\mathrm{Cr}^{\mathrm{III}}$ interconversion in the intracellular environment (Shanker et al. 2005; Viti et al. 2014; Kováćik et al. 2015), it shows that algal cells are exposed to a practically constant concentration of $\mathrm{Cr}^{\mathrm{VI}}$ throughout the test duration. The corresponding ECs50 values for $\mathrm{Cr}^{\mathrm{VI}}$ 
can therefore be confidently ascribed to this specific redox form and calculated from the concentrations initially added to the test medium.

On the other hand, marked and rapid changes in $\mathrm{Cr}$ speciation occurred in medium aliquots amended with $\mathrm{Cr}^{\mathrm{III}}$. At $\mathrm{t}=0$ and in the absence of algae, a single peak at a retention time of about $100 \mathrm{~s}$, corresponding to the hydrated $\mathrm{Cr}^{\mathrm{III}}$ ion, was observed (Figure 2B). The corresponding dissolved $\mathrm{Cr}^{\mathrm{III}}$ concentration determined by IC-ICP-MS was $57 \mu \mathrm{g} / \mathrm{L}$, in agreement with the expected value of $60 \mu \mathrm{g} / \mathrm{L}$. However, after $24 \mathrm{~h}$ of incubation, the peak area at $100 \mathrm{~s}$ had dropped by $99 \%$ and the corresponding dissolved $\mathrm{Cr}^{\mathrm{III}}$ concentration at $72 \mathrm{~h}$ was only $0.39 \mu \mathrm{g} / \mathrm{L}$ (Figure $2 \mathrm{~B}$ ). Starting from $24 \mathrm{~h}$ after spiking, two additional peaks were observed at retention times around $45 \mathrm{~s}$ and $75 \mathrm{~s}$ (Figure 2B). Considering the measured $\mathrm{pH}$ range of the test medium (7.5-7.9 for medium aliquouts amended with $\mathrm{Cr}^{\mathrm{III}}$ concentrations between 20 and $1250 \mu \mathrm{g} \mathrm{Cr} / \mathrm{L}$ ), $\mathrm{Cr}^{\mathrm{III}}$ is expected to rapidly undergo hydrolysis (Rai et al. 1989; Richard and Bourg 1991; Kotaś and Stasicka 2000) and the peaks at 45 and 75 s likely correspond to the hydrolytic $\mathrm{Cr}^{\mathrm{III}}$ complexes $\mathrm{Cr}(\mathrm{OH})^{2+}$ and $\mathrm{Cr}(\mathrm{OH})_{3}{ }^{0}$ (Séby et al. 2003).Addition of $5 \mu \mathrm{g} / \mathrm{L}$ of $\mathrm{Cr}^{\mathrm{VI}}$ to an aliquot of the solution initially spiked with $60 \mu \mathrm{g} / \mathrm{L}$ of $\mathrm{Cr}^{\mathrm{III}}$ and aged for $4 \mathrm{~h}$ resulted in the expected $\mathrm{Cr}^{\mathrm{VI}}$ peak at $50 \mathrm{~s}$, thus confirming that the peak at $45 \mathrm{~s}$ was not the results of an oxidation of $\mathrm{Cr}^{\mathrm{III}}$ to $\mathrm{Cr}^{\mathrm{VI}}$ during the experiment (Figures $2 \mathrm{C}$ and S6).

As already seen in the previous section, for an initial concentration of $60 \mu \mathrm{g} / \mathrm{L}$ of $\mathrm{Cr}^{\mathrm{III}}$, speciation calculations using Visual Minteq suggest that, at equilibrium, the positively charged species $\mathrm{Cr}(\mathrm{OH})_{2}{ }^{+}$and $\mathrm{CrOH}^{2+}$ should represent about $3.5 \%$ of the total in the observed $\mathrm{pH}$ range of 7.8-7.9. Assuming a dissolved $\mathrm{Cr}$ concentration of $11 \mu \mathrm{g} \mathrm{Cr} / \mathrm{L}$ after $72 \mathrm{~h}$ of incubation (see previous section and figure 1), the theoretical concentration of positively charged $\mathrm{Cr}$ species at the end of the exposure period would be $0.2-0.4 \mu \mathrm{g} / \mathrm{L}$; in agreement with the IC-ICP-MS speciation results (Figure 2B).

Samples spiked with $\mathrm{Cr}^{\mathrm{III}}$ in the presence of algae showed the three distinct peaks at retention times of about $100 \mathrm{~s}, 75 \mathrm{~s}$, and $45 \mathrm{~s}$ already at $\mathrm{t}=0$ (Figure S6). The area of all peaks rapidly decreased and became practically negligible after 24 hours of incubation (Figure S6). In the presence of algae, the concentration of hydrated $\mathrm{Cr}^{\mathrm{III}}$ (peak at $100 \mathrm{~s}$ ) decreased from $30 \mu \mathrm{g} / \mathrm{L}$ at $\mathrm{t}=0$ to $0.14 \mu \mathrm{g} / \mathrm{L}$ at $\mathrm{t}=72 \mathrm{~h}$ (Figure S6). The discrepancy between the measured $(30 \mu \mathrm{g} / \mathrm{L})$ and expected concentration $(60 \mu \mathrm{g} / \mathrm{L})$ at $\mathrm{t}=0$ can be explained by a more rapid formation of hydrolysis products. Indeed, the presence of particular microenvironments with increased $\mathrm{pH}$ around algal cells and colonies was reported to enhance Fe hydrolysis (Sunda and Huntsman 2003) and an analogous phenomenon may occur in the case of $\mathrm{Cr}^{\mathrm{III}}$. Again, no peak indicative of the formation of $\mathrm{Cr}^{\mathrm{VI}}$ was identified throughout the experiment duration so that the ecotoxicological effects discussed previously (section Chromium ecotoxicity in Results and Discussion) can be ascribed to $\mathrm{Cr}^{\mathrm{III}}$.

The disappearance of the chromatographic peak of hydrated $\mathrm{Cr}^{\mathrm{III}}(\mathrm{t}=100 \mathrm{~s})$ between 0 and 24 $\mathrm{h}$ of incubation prompted us to examine the changes in $\mathrm{Cr}^{\mathrm{III}}$ speciation at shorter time intervals. Note that, given the absence of calibration standards for the peaks at 45 and $75 \mathrm{~s}$, the changes in the relative importance of the chromatographic peaks can be discussed solely on the basis of their signal intensities. Immediately after spiking, $84 \%$ of dissolved $\mathrm{Cr}$ was present as hydrated $\mathrm{Cr}^{\text {III }}$ (retention time $100 \mathrm{~s}$ ) with the peaks at $75 \mathrm{~s}$ and $45 \mathrm{~s}$ representing about $8 \%$ of the total signal each (Figures $2 \mathrm{C}$ and 3). The peak of hydrated ionic $\mathrm{Cr}^{\mathrm{III}}$ at $100 \mathrm{~s}$ decreased very rapidly and was only $2 \%$ of the initial dissolved $\mathrm{Cr}$ concentration after 6 hours of incubation (Figure 3). At the same time, the peak at $75 \mathrm{~s}$ increased up to $56 \%$ of the total signal 1 hour after spiking and then slowly decreased to $40 \%$ after $6 \mathrm{~h}$. The peak at $45 \mathrm{~s}$ accounted for 7 and $10 \%$ of the total signal regardless of the incubation time (Figure 3). Both the sum of the signals of the three peaks and the corresponding dissolved $\mathrm{Cr}$ signal (assayed 
by ICP-MS) decreased by $50 \%$ and $40 \%$ compared with their respective initial values (Figure 3).

Samples collected after 24,48 , and $72 \mathrm{~h}$ of incubation confirmed the initial decreasing trend and, in the case of dissolved $\mathrm{Cr}$, were comparable with the results obtained by FAAS (Figure 1). The difference between dissolved $\mathrm{Cr}$ (ICP-MS) and the sum of various $\mathrm{Cr}$ peaks (IC-ICPMS) may be due to nanoparticle formation depositing in the column and going undetected. On the other hand, the signal of total $\mathrm{Cr}$ (in terms of relative intensity measured by ICP-MS) remained within $20 \%$ of the initial value (Figure 3). Overall, the rapid changes in $\mathrm{Cr}^{\mathrm{III}}$ speciation added to the test medium (particularly the disappearance of ionic $\mathrm{Cr}^{\mathrm{III}}$ in less than 2 h) arise the question of which $\mathrm{Cr}^{\mathrm{III}}$ species are actually responsible for the observed decrease in algal biomass during ecotoxicity testing. These considerations will be developed later in the text (section Implications for $\mathrm{Cr}$ hazard and risk assessment) after the presentation of the results confirming the formation of Cr-bearing particles in the test medium.

\section{Formation of chromium (nano)particles}

NTA analysis showed that colloidal particles formed within minutes after adding soluble $\mathrm{Cr}^{\mathrm{III}}$ into the test medium. Particle concentration and size ranged between $9.64 \times 10^{8}$ and $29.7 \times$ $10^{8}$ particles $/ \mathrm{mL}$ and 80 and $140 \mathrm{~nm}$, respectively (Figure 4). The particle concentration was $0.17 \pm 0.10 \times 10^{8}$ particles $/ \mathrm{mL}$ in test medium without added $\mathrm{Cr}^{\mathrm{III}}$ (Figure 4). Filtration $(0.22$ $\mu \mathrm{m})$ of $\mathrm{Cr}^{\mathrm{III}}$-amended aliquots of test medium lowered particle concentration to around $0.6 \times$ $10^{8}$ particles $/ \mathrm{mL}$, but did not decrease their size by more than $25 \%$ (Figure 4 ). Total Cr concentration remained within $\pm 20 \%$ of initial value over the entire experiment duration. Dissolved $\mathrm{Cr}$ concentrations also did not change during the first $2 \mathrm{~h}$ of incubation, but then progressively decreased to $26 \%$ of the initial value after $72 \mathrm{~h}$ (Figure 4 ). The concomitant removal of particles and decrease in dissolved $\mathrm{Cr}$ concentration (Figure 4) confirms the formation of $\mathrm{Cr}$ containing (nano)particles starting from initially soluble $\mathrm{Cr}^{\mathrm{III}}$ salts for incubation times $>24 \mathrm{~h}$ (Figure 4). The experimental decrease of dissolved $\mathrm{Cr}$ concentrations is in agreement with the theoretical calculation performed with Visual Minteq (see Chromium ecotoxicity in Results and discussion).

Analysis by spICP-MS confirmed that the nanoparticles formed immediately after spiking actually contained $\mathrm{Cr}$ (Figure S11). The orders of magnitude of size is similar to those measured using NTA (Figure S11 and Figure 4), at least when using the assumed composition and shape (Table S3). On the other hand, spICP-MS detected an increase in particle number from $5 \times 10^{6}(\mathrm{t} \leq 24 \mathrm{~h})$ to $2 \times 10^{8}(\mathrm{t} \geq 72 \mathrm{~h})$, suggesting that the mass percentage of $\mathrm{Cr}^{\mathrm{III}}$ occurring as particles increased from $4 \%$ at $0 \mathrm{~h}$ to $20 \%$ at $72 \mathrm{~h}$ to $76 \%$ at $96 \mathrm{~h}$. Differences in particle numbers estimated by spICP-MS and NTA likely arise from the specific technical features of the two methods. Large particles do not manage to pass a spray chamber and are therefore not measured during spICP-MS (Tuoriniemi et al. 2017), which therefore tends to favor small particles as long as they are larger than the detection limit of approx. $90 \mathrm{~nm}$. NTA, in contrast, preferentially detects relatively large particles that scatter more light and is less accurate in detecting relatively small particles. Note also that the particle size distributions detected with spICP-MS abruptly stop at the size detection limit. Thus, despite the two techniques yielding similar average particle sizes, NTA likely observes a fairly constant number concentration of relatively large particles that are mostly removed by filtration, while spICPMS observes an increase in the number of (relatively small) particles with time (Figure 4 and S11). At short incubation times, a very large mass of Cr may reside in the particle fraction that can pass a $0.22 \mu \mathrm{m}$ filter without being detected by neither NTA nor spICP-MS. Hence, a decrease $\mathrm{Cr}$ mass concentration is not observed when filtering samples at $0.22 \mu \mathrm{m}$ at short incubation times (Figure 4). Measurement of total and dissolved Fe (data not shown) allowed to exclude the formation of Fe-bearing particles (including mixed $\mathrm{Cr}$ - 
$\mathrm{Fe}$ (oxy)hydroxides) (Sass and Rai 1987) and thus the possibility of indirect ecotoxic effect of $\mathrm{Cr}^{\mathrm{III}}$ via sequestration of the essential nutrient Fe. Interestingly, model calculations with Visual Minteq predicted that the test medium should be oversaturated with respect to different mineral phases including several Fe-containing minerals and hydroxyapatite. The exact chemical nature of particles formed in Cr-spiked test medium clearly deserves further experimental investigation, especially at short incubation times for which the assumption of equilibrium is unlikely to be valid. Finally, removal of particles with sizes between 80 and $140 \mathrm{~nm}$ by filters with a $0.22 \mu \mathrm{m}$ nominal cut-off can be explained by an actual smaller cutoff of the filters' pores (She et al. 2008) or by the formation of larger particles undetectable via NTA and spICP-MS.

Measurements by SPC confirmed the presence of particles in the same range identified by NTA and spICP-MS, but also of particles larger than $300 \mathrm{~nm}$ in unfiltered test medium spiked with $\mathrm{Cr}^{\mathrm{III}}$ and incubated for 24, 48, and 72 hours (Figure 5 and S7). At $\mathrm{t}=0$, only particles between 50 and $150 \mathrm{~nm}$ were observed at a concentration of $3.2 \times 10^{5}$ particles $/ \mathrm{mL}$. After 24 hours, the concentration of particles between 50 and $200 \mathrm{~nm}$ increased to $6.1 \times 10^{6}$ particles $/ \mathrm{mL}$ and particles larger than $300 \mathrm{~nm}\left(8.5 \times 10^{3}\right.$ particles $\left./ \mathrm{mL}\right)$ had also appeared. Particles in the range 50-200 nm were still present after $48\left(6.5 \times 10^{6}\right.$ particles $\left./ \mathrm{mL}\right)$ and $72 \mathrm{~h}$ $\left(9.8 \times 10^{6}\right.$ particles $\left./ \mathrm{mL}\right)$ of incubation, while particles larger than $300 \mathrm{~nm}$ eventually disappeared after $72 \mathrm{~h}$ (Figure 5). The latter observation suggests the formation of particles too large to be measured by the instruments or, more likely, settling too quickly to be effectively sampled by the instrument.

Based on the analysis of total and dissolved $\mathrm{Cr}$ in the samples subject to SPC measurements (figure $\mathrm{S} 7$ ), $45 \mu \mathrm{g}$ of $\mathrm{Cr}$ (75\% of the $\mathrm{Cr}^{\mathrm{III}}$ initially added to the test medium) had been incorporated in the observed particles after 72 hours. This result agrees well with the corresponding Visual Minteq calculations (see section Cr ecotoxicity in Results and discussion for details). Assuming a density of $3.11 \mathrm{~g} / \mathrm{cm}^{3}$ for the amorphous $\mathrm{Cr}$ oxyhydroxides likely occurring in the medium, the total volume of the particles would be approx. $1.45 \times 10^{-14} \mathrm{~m}^{3} / \mathrm{mL}$. Given an approximate volume of $5.24 \times 10^{-22} \mathrm{~m}^{3}$ for an individual (spherical) particle with a diameter of $100 \mathrm{~nm}$, a mass of $\mathrm{Cr}$ of $45 \mu \mathrm{g}$ would be enough to form $2.76 \times 10^{7}$ particles/mL. The presence of larger particles, unaccounted for in the previous calculation, can be invoked to explain the difference between calculations and SPC measurements.

\section{Implications for Cr hazard and risk assessment}

Our results show that $\mathrm{Cr}^{\mathrm{III}}$ speciation into a standardized ecotoxicological test medium for algae changes within a few hours after spiking; even when the total $\mathrm{Cr}^{\mathrm{III}}$ concentration remains comparatively stable. Similar, although less detailed, investigations on daphnids (Ponti et al. 2014) and bacteria (Bencheikh-Latmani et al. 2007) suggest that such behavior may be common in ecotoxicological media whose composition favors the formation of $\mathrm{Cr}^{\mathrm{III}}$ hydroxides. Thus, new ecotoxicological data for the hazard assessment of $\mathrm{Cr}^{\mathrm{III}}$ must be obtained by considering the recommendations originally developed for sparingly soluble substances (ISO 14442 2006) [46]. In particular, in the case of marked differences (> 20\%) between nominal and actual concentration, the corresponding EC50 for $\mathrm{Cr}^{\mathrm{III}}$ must be calculated as the TWM of the dissolved concentration (OECD 2012). The excellent agreement between experimental results and thermodynamic modeling of speciation equally suggests that our observations could have a broader validity, although the kinetics of temporal speciation changes may vary across media and as a function of initial $\mathrm{Cr}^{\mathrm{III}}$ concentration. Furthermore, following our IC-ICPMS results, the question of the actual $\mathrm{Cr}^{\mathrm{III}}$ species responsible for the observed ecotoxicological effects in living organisms deserves additional study. An application of the biotic ligand model to the study of root elongation in barley 
(Song et al. 2014) suggested $\mathrm{Cr}^{3+}$ and $\mathrm{Cr}(\mathrm{OH})^{2+}$ as the two biologically active chemical species in controlling the effects of $\mathrm{Cr}^{\mathrm{III}}$. However, the rapid disappearance $(<2 \mathrm{~h})$ of ionic $\mathrm{Cr}$ from the test medium questions the role of such species in determining the observed algal response. One possibility is that a pulse exposure to $60 \mu \mathrm{g} / \mathrm{L}$ of truly dissolved $\mathrm{Cr}^{\mathrm{III}}$ at the beginning of the test can cause a 50\% reduction in algal biomass after incubation over $72 \mathrm{~h}$. Alternatively, the residual concentration of ionic $\mathrm{Cr}^{\mathrm{III}}$ after $2 \mathrm{~h}$ (less than $1 \mu \mathrm{g} / \mathrm{L}$ ) determines the effect observed at the end of the test or the other $\mathrm{Cr}^{\mathrm{III}}$ species also contribute to the observed toxicity. The formation of some Cr-bearing (nano)particles over the course of the test also points to a possible nano-ecotoxicological dimension in the toxicity of $\mathrm{Cr}^{\mathrm{III}}$ to algae. In particular, freshly formed $\mathrm{Cr}(\mathrm{OH})_{3}$ particles can lead to the formation of "transiently available CrIII species" which may be highly toxic (Bencheikh-Latmani et al. 2007). The existence of monomeric and polymeric $\mathrm{Cr}^{\mathrm{III}}$ being documented in environmental samples $(\mathrm{Hu}$ et al. 2016), both $\mathrm{Cr}$ hydroxides and Cr-bearing (nano)particles may have an ecotoxicological role outside laboratory settings and deserve consideration in risk assessment for $\mathrm{Cr}^{\mathrm{III}}$. The present study does not question the high ecotoxicity of $\mathrm{Cr}^{\mathrm{VI}}$, but it adds to the growing evidence that the biological effects of $\mathrm{Cr}^{\text {III }}$ strongly depend on the composition of the medium used for testing and are likely underestimated (Lira-Silva et al. 2011; Ponti et al. 2014). In this context, the paradigm ' $\mathrm{Cr}$ VI is more toxic than $\mathrm{Cr}^{\mathrm{III}}$, increasingly appears as an oversimplified representation of environmental reality. In this context, more detailed studies on the speciation $\mathrm{Cr}^{\mathrm{III}}$ in standardized ecotoxicological laboratory settings are highly desirable for at least three reasons. First, reduction of $\mathrm{Cr}^{\mathrm{VI}}$ to $\mathrm{Cr}^{\mathrm{III}}$ is a typical strategy for remediation of $\mathrm{Cr}$ contaminated matrices and environments; second $\mathrm{Cr}$ contamination remains a serious environmental problem in several low to middle income countries whose economic activity is linked with the material demands of the current lifestyle in developed countries (Pure Earth and Green Cross 2016); third the safe perspective use of $\mathrm{Cr}_{2} \mathrm{O}_{3}$ nanoparticles is linked to their intrinsic properties, but also to the possible release of soluble $\mathrm{Cr}$ in either redox forms (Horie et al. 2013; da Costa et al. 2016; Puerari et al. 2016). In all cases, the appropriate knowledge of the actual ecotoxicity of $\mathrm{Cr}^{\mathrm{VI}}$ and $\mathrm{Cr}^{\mathrm{III}}$ necessary to assess the environmental risks of $\mathrm{Cr}$ appears incomplete. Identifying the exact chemical species responsible for ecotoxicological effects, especially in the case of $\mathrm{Cr}^{\mathrm{III}}$, will facilitate extrapolation of laboratory findings to complex environmental realities and the associated remediation/management decision.

Supplemental data - The Supplemental Data are available on the Wiley Online Library at DOI: 10.1002/etc.xxx. Details for IC-ICP-MS experiments and analytical procedures, temporal evolution of dissolved $\mathrm{Cr}^{\mathrm{III}}$ and $\mathrm{Cr}^{\mathrm{VI}}$ concentrations, complementary IC-ICP-MS results, optimization and details of NTA and spICP-MS procedures and additional measurements of particle size distribution and number by SPC, NTA and spICP-MS.

\section{Acknowledgment}

This work is part of the $\mathrm{PhD}$ thesis of I. Aharchaou who is supported by the French Ministry of Education. The financial support of the CNRS (project EC2CO Insokintox) is greatly acknowledged. We thank A. Garnier (LHN, ANSES, Nancy) for help with IC-ICP-MS analysis. The contributions of S. Cambier were in part made possible within NANION (FNR/12/SR/4009651-Fonds National de la Recherche Luxembourg). We are grateful to E. Szalinska (AGH University of Science and Technology, Krakow, Poland) for her help in some experiments. D. Vignati and G. Cornelis acknowledge the support of COST action ES1205 (STSM 35421). 


\section{REFERENCES}

Anses. Méthode d'analyse du chrome hexavalent dans les eaux. [accessed 2016 Apr 11]. https://www.anses.fr/fr/system/files/MethodeChromeHexavalentEaux-Consultation.pdf.

Bencheikh-Latmani R, Obraztsova A, Mackey MR, Ellisman MH, Tebo BM. 2007. Toxicity of $\mathrm{Cr}(\mathrm{III})$ to Shewanella sp. Strain MR-4 during Cr(VI) Reduction. Environ. Sci. Technol. 41:214-220. doi:10.1021/es0622655.

Bobrowski A, Baś B, Dominik J, Niewiara E, Szalińska E, Vignati D, Zarbski J. 2004. Chromium speciation study in polluted waters using catalytic adsorptive stripping voltammetry and tangential flow filtration. Talanta 63:1003-1012. doi:10.1016/j.talanta.2004.01.004.

Carr, B, Wright, M. 2013. Nanoparticle Tracking Analysis. [accessed 2016 Mar 21]. http://particularsciences.ie/psl/brochures/supplier_brochures_pdf/nta_brochure.pdf.

Chapman GA, Ota S, Recht F, Corvallis Environmental Research Laboratory. 1980. Effects of water hardness on the toxicity of metals to Daphnia magna: status report - January 1980. Corvallis, Ore.: U.S. Environmental Protection Agency, Corvallis Environmental Research Laboratory.

Cheung KH, Gu J-D. 2007. Mechanism of hexavalent chromium detoxification by microorganisms and bioremediation application potential: A review. Int. Biodeterior. Biodegrad. 59:8-15. doi:10.1016/j.ibiod.2006.05.002.

da Costa CH da, Perreault F, Oukarroum A, Melegari SP, Popovic R, Matias WG. 2016. Effect of chromium oxide (III) nanoparticles on the production of reactive oxygen species and photosystem II activity in the green alga Chlamydomonas reinhardtii. Sci. Total Environ. 565:951-960. doi:10.1016/j.scitotenv.2016.01.028.

Dazy M, Béraud E, Cotelle S, Meux E, Masfaraud J-F, Férard J-F. 2008. Antioxidant enzyme activities as affected by trivalent and hexavalent chromium species in Fontinalis antipyretica Hedw. Chemosphere 73:281-290. doi:10.1016/j.chemosphere.2008.06.044.

de Paiva Magalhães D, da Costa Marques MR, Baptista DF, Buss DF. 2015. Metal bioavailability and toxicity in freshwaters. Environmental Chemistry Letters 13:69-87.

Didur O, Dewez D, Popovic R. 2013. Alteration of chromium effect on photosystem II activity in Chlamydomonas reinhardtii cultures under different synchronized state of the cell cycle. Environ. Sci. Pollut. Res. 20:1870-1875. doi:10.1007/s11356-012-1389-8.

Dominik J, Vignati D a. L, Koukal B, Pereira de Abreu M-H, Kottelat R, Szalinska E, Baś B, Bobrowski A. 2007. Speciation and Environmental Fate of Chromium in Rivers Contaminated with Tannery Effluents. Eng. Life Sci. 7:155-169. doi:10.1002/elsc.200620182.

Vindimian.E. 2010. REGTOX: macro Excel $^{\mathrm{TM}}$ for dose-response modelling.

Fairbrother A, Wenstel R, Sappington K, Wood W. 2007. Framework for Metals Risk Assessment. Ecotoxicol. Environ. Saf. 68:145-227. doi:10.1016/j.ecoenv.2007.03.015. 

Principles of Sound Ecotoxicology. Environ. Sci. Technol. 48:3100-3111.

Holdway D. 1988. The toxicity of chromium to fish. In Nriagu JO, Nieboer E, eds, Chromium in the natural and human environments. John Wiley \& Sons, pp. 369-397.

Horie M, Nishio K, Endoh S, Kato H, Fujita K, Miyauchi A, Nakamura A, Kinugasa S, Yamamoto K, Niki E, et al. 2013. Chromium(III) oxide nanoparticles induced remarkable oxidative stress and apoptosis on culture cells. Environ. Toxicol. 28:61-75. doi:10.1002/tox.20695.

Hu L, Cai Y, Jiang G. 2016. Occurrence and speciation of polymeric chromium(III), monomeric chromium(III) and chromium(VI) in environmental samples. Chemosphere 156:14-20. doi:10.1016/j.chemosphere.2016.04.100.

Munn S. J Allanou, R Aschberger, K Berthault, F Cosgrove, O Luotamo, M Vegro. 2005. Chromium trioxide, sodium chromate, sodium dichromate, ammonium dichromate, potassium dichromate, EUR 21508 EN. European Union Risk Assessment Report, 53..

ISO 14442. 2006. Water quality -- Guidelines for algal growth inhibition tests with poorly soluble materials, volatile compounds, metals and waste water.

Kotaś J, Stasicka Z. 2000. Chromium occurrence in the environment and methods of its speciation. Environ. Pollut. 107:263-283. doi:10.1016/S0269-7491(99)00168-2.

Kováčik J, Babula P, Hedbavny J, Kryštofová O, Provaznik I. 2015. Physiology and methodology of chromium toxicity using alga Scenedesmus quadricauda as model object. Chemosphere 120:23-30. doi:10.1016/j.chemosphere.2014.05.074.

Labra M, Bernasconi M, Grassi F, De Mattia F, Sgorbati S, Airoldi R, Citterio S. 2007. Toxic and genotoxic effects of potassium dichromate in Pseudokirchneriella subcapitata detected by microscopy and AFLP marker analysis. Aquat. Bot. 86:229-235.

doi:10.1016/j.aquabot.2006.10.006.

Lin C-J. 2002. The Chemical Transformations of Chromium in Natural Waters - A Model Study. Water. Air. Soil Pollut. 139:137-158. doi:10.1023/A:1015870907389.

Lira-Silva E, Ramírez-Lima IS, Olín-Sandoval V, García-García JD, García-Contreras R, Moreno-Sánchez R, Jasso-Chávez R. 2011. Removal, accumulation and resistance to chromium in heterotrophic Euglena gracilis. J. Hazard. Mater. 193:216-224. doi:10.1016/j.jhazmat.2011.07.056.

Liu J, Fu J, Ning X 'an, Sun S, Wang Y, Xie W, Huang S, Zhong S. 2015. An experimental and thermodynamic equilibrium investigation of the $\mathrm{Pb}, \mathrm{Zn}, \mathrm{Cr}, \mathrm{Cu}, \mathrm{Mn}$ and $\mathrm{Ni}$ partitioning during sewage sludge incineration. J. Environ. Sci. 35:43-54. doi:10.1016/j.jes.2015.01.027.

Mason RP. 2013. Trace Metals in Aquatic Systems. John Wiley \& Sons. 
Masscheleyn PH, Pardue JH, DeLaune RD, Patrick J WH. 1992. Chromium Redox Chemistry in a Lower Mississippi Valley Bottomland Hardwood Wetland. Environ. Sci. Technol. 26:1217-1226. doi:10.1021/es50002a611.

Morel, F.M.M. 1983. Principles of Aquatic Chemistry. Wiley, New York.

OECD. 2011. Test No. 201: Freshwater Alga and Cyanobacteria, Growth Inhibition Test. Paris: Organisation for Economic Co-operation and Development. [accessed 2015 Sep 18]. http://www.oecd-ilibrary.org/content/book/9789264069923-en.

OECD. 2012. Test No. 211: Daphnia magna Reproduction Test. Paris: Organisation for Economic Co-operation and Development. [accessed 2015 Sep 18]. http://www.oecdilibrary.org/content/book/9789264185203-en.

World Health Organization. 2009. Inorganic Chromium(III) Compounds.

World Health Organization. 2013. Inorganic Chromium(VI) Compounds.

Pace HE, Rogers NJ, Jarolimek C, Coleman VA, Higgins CP, Ranville JF. 2011. Determining Transport Efficiency for the Purpose of Counting and Sizing Nanoparticles via Single Particle Inductively Coupled Plasma Mass Spectrometry. Anal. Chem. 83:9361-9369. doi:10.1021/ac201952t.

Ponti B, Bettinetti R, Dossi C, Vignati DAL. 2014. How reliable are data for the ecotoxicity of trivalent chromium to Daphnia magna? Environ. Toxicol. Chem. 33:2280-2287. doi:10.1002/etc.2672.

Puerari RC, da Costa CH, Vicentini DS, Fuzinatto CF, Melegari SP, Schmidt ÉC, Bouzon ZL, Matias WG. 2016. Synthesis, characterization and toxicological evaluation of $\mathrm{Cr} 2 \mathrm{O} 3$ nanoparticles using Daphnia magna and Aliivibrio fischeri. Ecotoxicol. Environ. Saf. 128:3643. doi:10.1016/j.ecoenv.2016.02.011.

Pure Earth, Green Cross. 2016. The World's Worst Pollution Problems 2016: The Toxics Beneath Our Feet. [accessed 2016 Nov 19].

Rai D, Eary LE, Zachara JM. 1989. Environmental chemistry of chromium. Sci. Total Environ. 86:15-23. doi:10.1016/0048-9697(89)90189-7.

Richard FC, Bourg ACM. 1991. Aqueous geochemistry of chromium: A review. Water Res. 25:807-816. doi:10.1016/0043-1354(91)90160-R.

Rossé P, Loizeau J-L. 2003. Use of single particle counters for the determination of the number and size distribution of colloids in natural surface waters. Colloids Surf. Physicochem. Eng. Asp. 217:109-120. doi:10.1016/S0927-7757(02)00565-4.

Sacher F, Raue B, Klinger J, Brauch H-J. 1999. Simultaneous Determination of Cr(III) and $\mathrm{Cr}(\mathrm{VI})$ in Ground and Drinking Waters by IC-ICP-MS. Int. J. Environ. Anal. Chem. 74:191201. doi:10.1080/03067319908031425. 
Saputro S, Yoshimura K, Matsuoka S, Takehara K, Narsito, Aizawa J, Tennichi Y. 2014. Speciation of dissolved chromium and the mechanisms controlling its concentration in natural water. Chem. Geol. 364:33-41. doi:10.1016/j.chemgeo.2013.11.024.

Sass BM, Rai D. 1987. Solubility of amorphous chromium(III)-iron(III) hydroxide solid solutions. Inorg. Chem. 26:2228-2232. doi:10.1021/ic00261a013.

Séby F, Charles S, Gagean M, Garraud H, Donard OFX. 2003. Chromium speciation by hyphenation of high-performance liquid chromatography to inductively coupled plasma-mass spectrometry-study of the influence of interfering ions. J. Anal. At. Spectrom. 18:13861390. doi:10.1039/B306249J.

Shanker AK, Cervantes C, Loza-Tavera H, Avudainayagam S. 2005. Chromium toxicity in plants. Environ. Int. 31:739-753. doi:10.1016/j.envint.2005.02.003.

She FH, Tung KL, Kong LX. 2008. Calculation of effective pore diameters in porous filtration membranes with image analysis. Robot. Comput.-Integr. Manuf. 24:427-434. doi:10.1016/j.rcim.2007.02.023.

Song N, Zhong X, Li B, Li J, Wei D, Ma Y. 2014. Development of a Multi-Species Biotic Ligand Model Predicting the Toxicity of Trivalent Chromium to Barley Root Elongation in Solution Culture. PLoS ONE 9:e105174. doi:10.1371/journal.pone.0105174.

Sunda W, Huntsman S. 2003. Effect of pH, light, and temperature on Fe-EDTA chelation and Fe hydrolysis in seawater. Mar. Chem. 84:35-47. doi:10.1016/S0304-4203(03)00101-4.

Thompson SL, Manning FCR, McColl SM. 2002. Comparison of the Toxicity of Chromium III and Chromium VI to Cyanobacteria. Bull. Environ. Contam. Toxicol. 69:286-293. doi:10.1007/s00128-002-0059-9.

Tuoriniemi J, Cornelis G, Hassellöv M. 2015. A new peak recognition algorithm for detection of ultra-small nano-particles by single particle ICP-MS using rapid time resolved data acquisition on a sector-field mass spectrometer. J. Anal. At. Spectrom. 30:1723-1729. doi:10.1039/C5JA00113G.

Tuoriniemi J, Jürgens MD, Hassellöv M, Cornelis G. 2017. Size dependence of silver nanoparticle removal in a wastewater treatment plant mesocosm measured by FAST single particle ICP-MS. Environ. Sci. Nano 4:1189-1197. doi:10.1039/C6EN00650G.

Vignati DAL, Beye ML, Dominik J, Klingemann AO, Filella M, Bobrowski A, Ferrari BJ. 2008. Temporal Decrease of Trivalent Chromium Concentration in a Standardized Algal Culture Medium: Experimental Results and Implications for Toxicity Evaluation. Bull. Environ. Contam. Toxicol. 80:305-310. doi:10.1007/s00128-008-9379-8.

Vignati DAL, Dominik J, Beye ML, Pettine M, Ferrari BJD. 2010. Chromium(VI) is more toxic than chromium(III) to freshwater algae: A paradigm to revise? Ecotoxicol. Environ. Saf. 73:743-749. doi:10.1016/j.ecoenv.2010.01.011. 
Viti C, Marchi E, Decorosi F, Giovannetti L. 2014. Molecular mechanisms of Cr(VI) resistance in bacteria and fungi. FEMS Microbiol. Rev. 38:633-659. doi:10.1111/15746976.12051.

Volland S, Lütz C, Michalke B, Lütz-Meindl U. 2012. Intracellular chromium localization and cell physiological response in the unicellular alga Micrasterias. Aquat. Toxicol. 109:59-

800 69. doi:10.1016/j.aquatox.2011.11.013.

801

802

803

804

805

806

807

808

809 


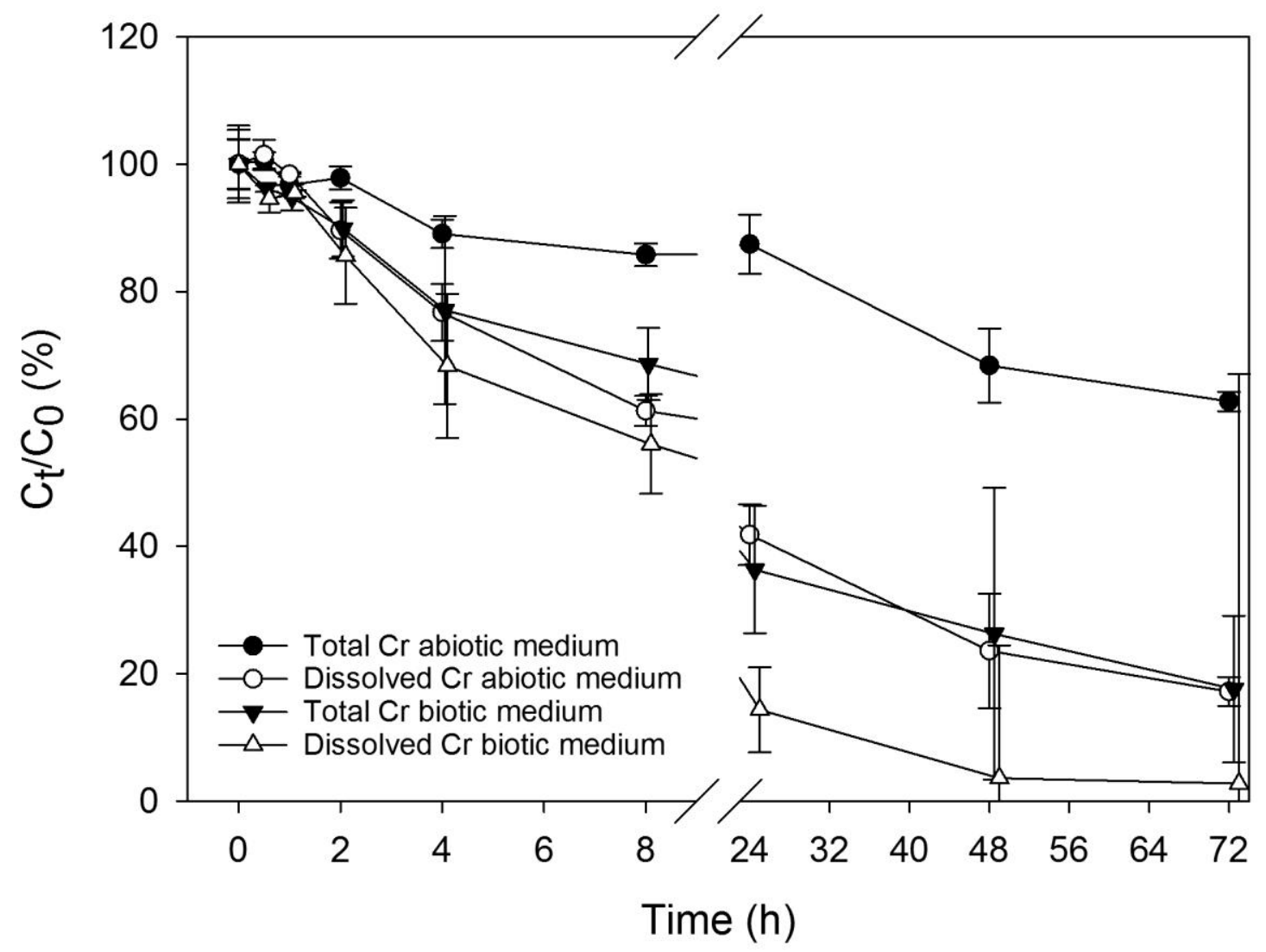

Figure 1. Temporal evolution (expressed as percentage of the value measured at $t=0$ ) of total and dissolved $(<0.22 \mu \mathrm{m}) \mathrm{Cr}$ concentrations in ISO medium amended with $\mathrm{CrCl}_{3} \cdot 6 \mathrm{H}_{2} \mathrm{O}$ at an initial concentration of $60 \mu \mathrm{g} \mathrm{Cr} / \mathrm{L}$ (nominal value). Error bars indicate one standard deviation (SD). Large SD after $72 \mathrm{~h}$ of incubation were caused by $\mathrm{Cr}$ concentration decreasing to values close to the instrumental detection limit. $\mathrm{C}_{0}$ and $\mathrm{C}_{\mathrm{t}}$ refer to total or dissolved $\mathrm{Cr}$ concentration measured at $\mathrm{t}=0$ and at the various incubation times, respectively. All data points were calculated on the basis of measured total and dissolved $\mathrm{Cr}$ values. The measured $\mathrm{pH}$ was 7.8 7.9 over the entire duration of the experiment. Data points for different incubation times were slightly nudged to visualize the corresponding error bars. 
Figure 2.
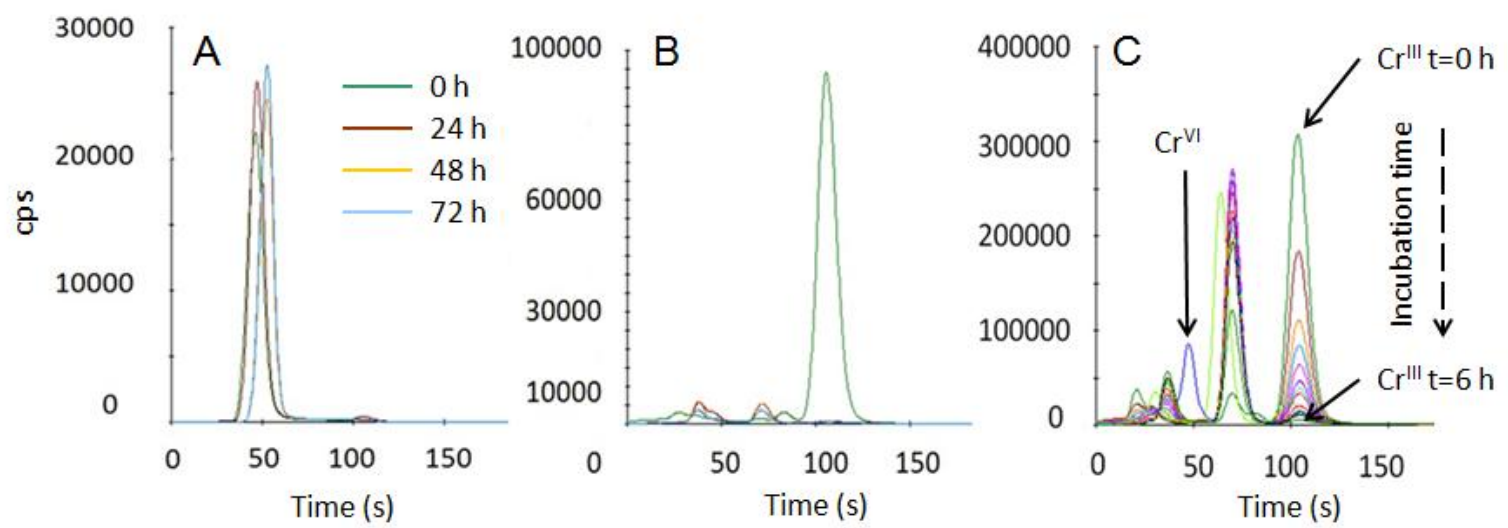

Figure 2. Chromatograms of test medium (without added algae) at different incubation times. Panels A and B: test medium amended with $115 \mu \mathrm{g} / \mathrm{L}$ of $\mathrm{Cr}^{\mathrm{VI}}\left(\mathrm{K}_{2} \mathrm{Cr}_{2} \mathrm{O}_{7}\right)$ (A) or $60 \mu \mathrm{g} / \mathrm{L}$ of $\mathrm{Cr}^{\mathrm{III}}\left(\mathrm{CrCl}_{3} \cdot 6 \mathrm{H}_{2} \mathrm{O}\right)(\mathrm{B})$ at $0 \mathrm{~h}, 24 \mathrm{~h}, 48 \mathrm{~h}$ or $72 \mathrm{~h}$ after spiking. Panel C: temporal evolution of chromatograms of test medium containing $60 \mu \mathrm{g} / \mathrm{L}$ of $\mathrm{Cr}^{\mathrm{III}}$ with measurements performed every 20 min during $6 \mathrm{~h}$. Note the peak of added $\mathrm{Cr}(\mathrm{VI})(5 \mu \mathrm{g} / \mathrm{L})$ at $50 \mathrm{~s}$. All solutions were filtered $(0.22 \mu \mathrm{m})$ immediately before analysis; cps (counts per second). Note the different scales on the y axes. 


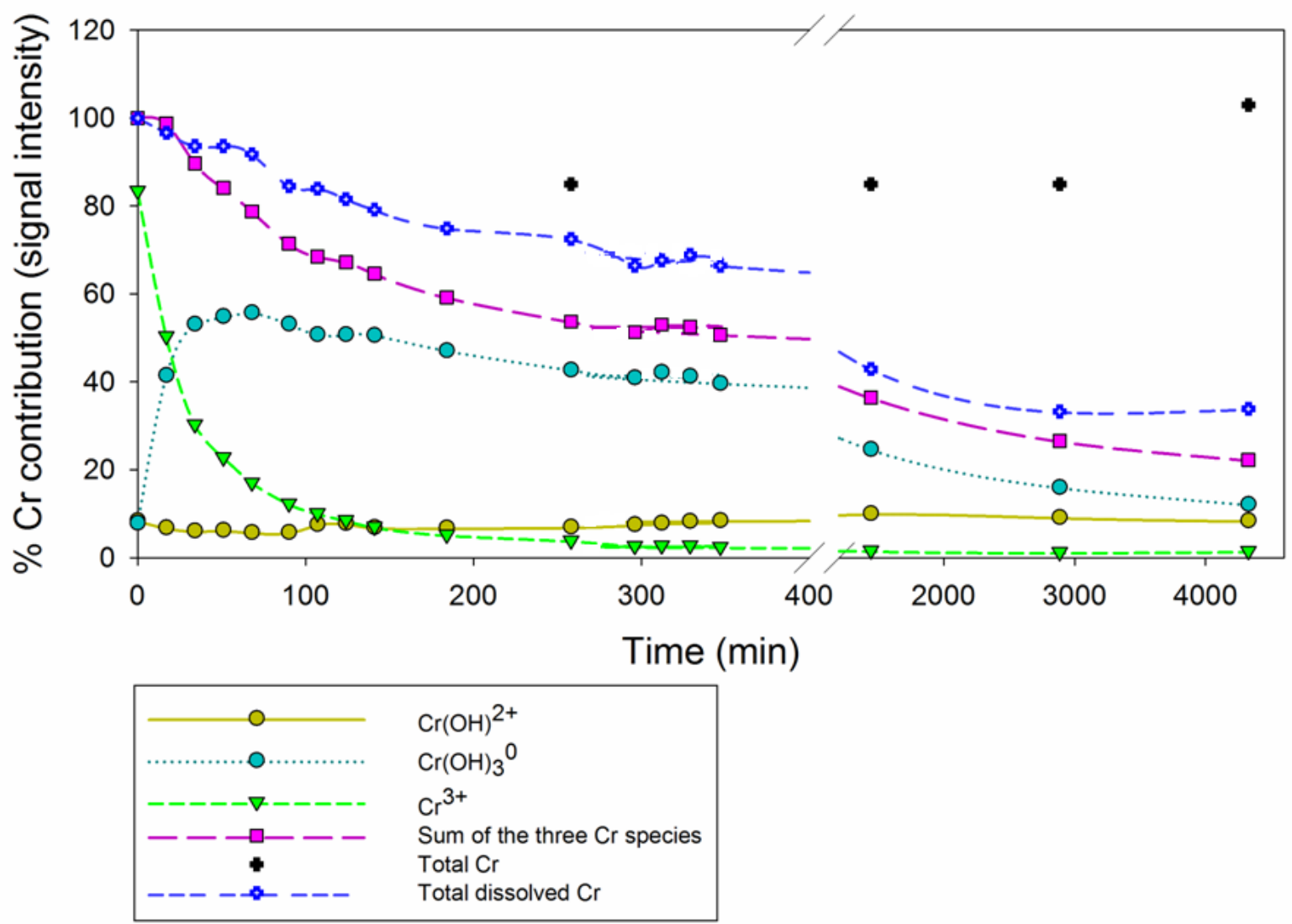

Figure 3. Temporal evolution of the relative abundances of three $\mathrm{Cr}^{\mathrm{III}}$ species $\left(\mathrm{Cr}(\mathrm{OH})^{2+}\right.$, yellow circles; $\mathrm{Cr}(\mathrm{OH})_{3}{ }^{0}$, turquoise circles; $\mathrm{Cr}^{3+}$, green triangles) in ISO medium spiked with $60 \mu \mathrm{g} \mathrm{Cr} / \mathrm{L}$ of $\mathrm{Cr}^{\mathrm{III}}\left(\mathrm{CrCl}_{3} \cdot 6 \mathrm{H}_{2} \mathrm{O}\right)$ determined by IC-ICP-MS. The sum of the three $\mathrm{Cr}$ species (pink squares) and the signals of total chromium (black crosses) and total dissolved chromium (filtered at $0.22 \mu \mathrm{m}$; blue crosses) are also indicated.

(1) 


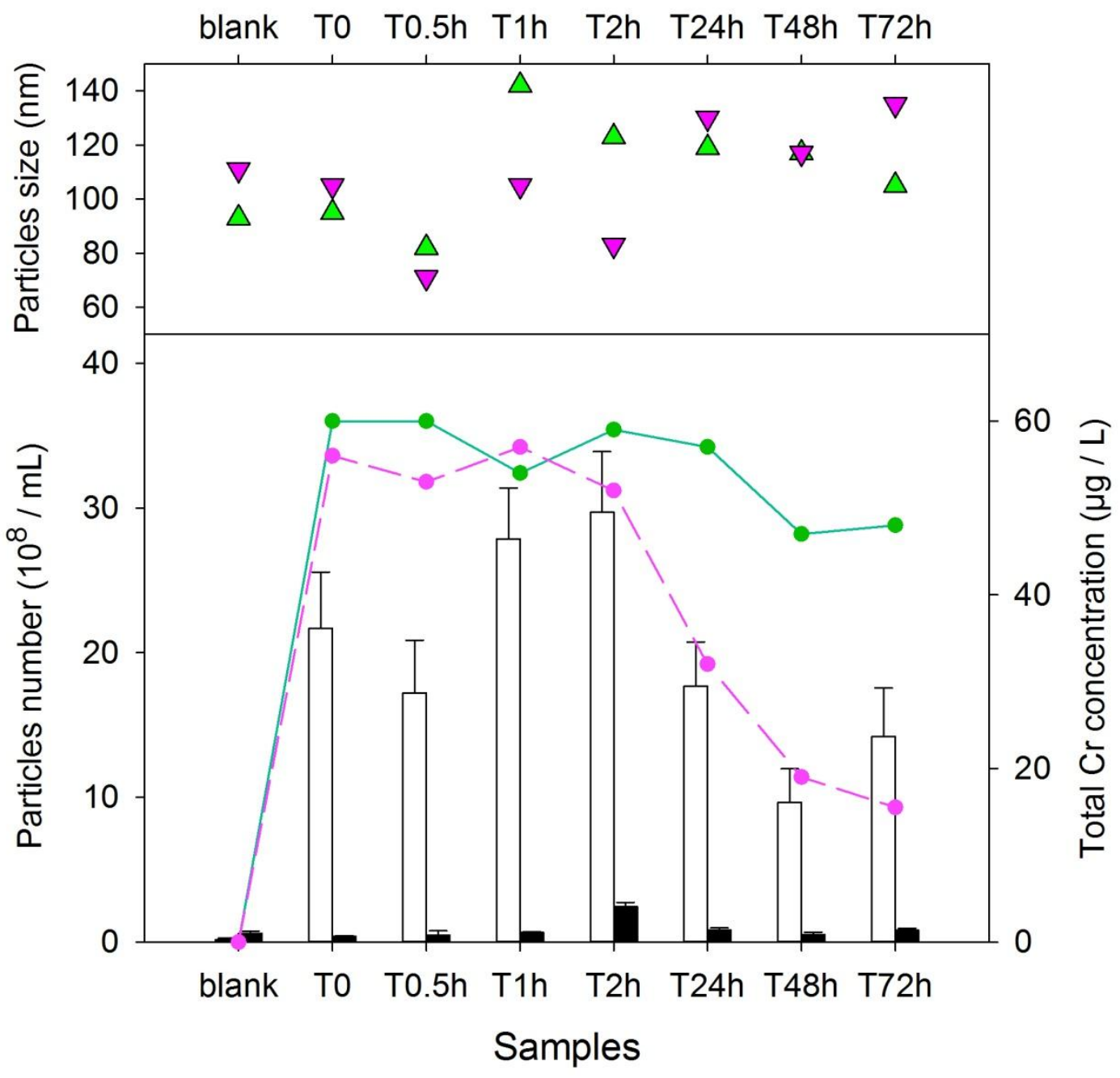

\begin{tabular}{|cl|}
\hline$\triangle$ & Particles size \\
$\nabla$ & Particles size in filtered samples $(0.22 \mu \mathrm{m})$ \\
\hline$\square$ & Particles number \\
$\square$ & Particles number in filtered samples $(0.22 \mu \mathrm{m})$ \\
$\square-$ & Total Cr concentration \\
$\square-\quad$ Total dissolved $\mathrm{Cr}$ concentration $(0.22 \mu \mathrm{m})$
\end{tabular}

Figure 4. Particle concentrations (bars), particle size (triangles) and $\mathrm{Cr}$ concentration (lines) in unfiltered and filtered $(0.22 \mu \mathrm{m})$ aliquots of ISO medium spiked (except for the sample 'Blank') with $60 \mu \mathrm{g} / \mathrm{L}$ of $\mathrm{Cr}^{\mathrm{III}}\left(\mathrm{CrCl}_{3} \cdot 6 \mathrm{H}_{2} \mathrm{O}\right)$ at different incubation times. Particle concentration and size measured by nanoparticle tracking analysis, $\mathrm{Cr}$ concentration measured by atomic absorption spectrometry. 


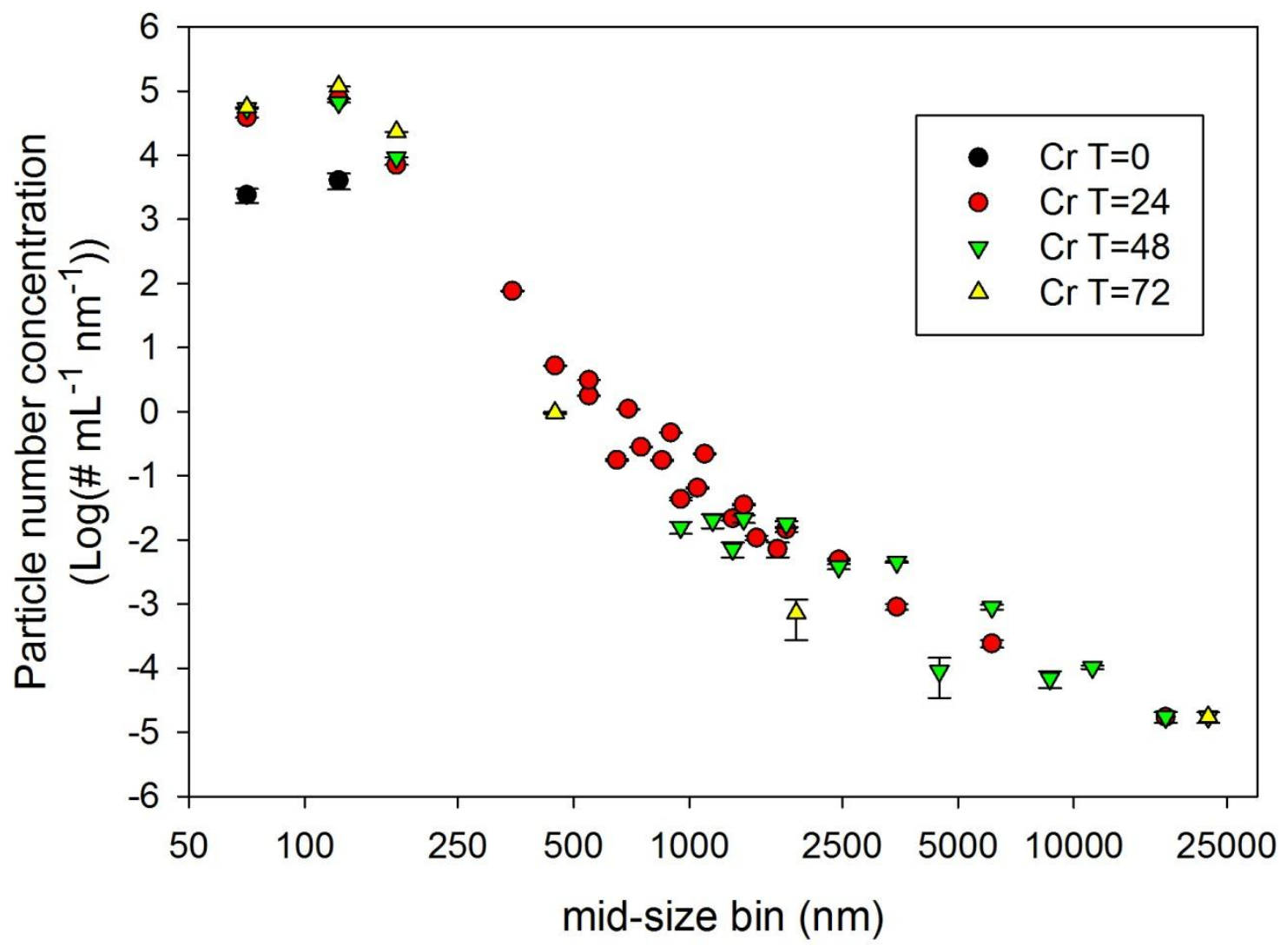

Figure 5. Particle size distribution and number of particles (in $\mathrm{mL}^{-1} \mathrm{~nm}^{-1}$ ) in test medium spiked with $\mathrm{Cr}^{\mathrm{III}}\left(\mathrm{CrCl}_{3} \cdot 6 \mathrm{H}_{2} \mathrm{O}\right)$ after 0 (black circles), 24 (red circles), 48 (green triangles) and $72 \mathrm{~h}$ (yellow triangles) of incubation. All measurements were performed by Single Particle Counter (SPC) at a sample flow rate of $64 \mathrm{~mL} / \mathrm{min}$. Results for each size class have been corrected for particle concentration in ISO medium without added $\mathrm{Cr}^{\mathrm{III}}$ (see figure $\mathrm{S} 7$ for the corresponding comparisons). To obtain the number of particles per $\mathrm{mL}$ in a given size range, the values on the y-axis must be multiplied for the corresponding size range (in $\mathrm{nm}$ ) on the $\mathrm{x}$-axis. 


\section{Supporting information}

\section{Chromium speciation in a standardized ecotoxicological medium:} implications for hazard and risk assessment

Imad Aharchaou $^{\mathrm{a}^{*}}$, Jean-Sébastien Py ${ }^{\mathrm{b}}$, Sébastien Cambier ${ }^{\mathrm{c}}$, Jean-Luc Loizeau ${ }^{\mathrm{d}}$, Geert Cornelis $^{\mathrm{e}}$, Philippe Rousselle ${ }^{\mathrm{a}}$, Eric Battaglia ${ }^{\mathrm{a}}$, Davide A.L. Vignati ${ }^{\mathrm{a}}$

${ }^{a}$ Laboratoire Interdisciplinaire des Environnements Continentaux LIEC-UMR 7360, Université de Lorraine and CNRS, 8 rue du Général Delestraint, 57070 Metz, France

${ }^{\mathrm{b}}$ Agence nationale de sécurité sanitaire de l'alimentation, de l'environnement et du travail ANSES-Laboratoire d'hydrologie de Nancy, 40 rue Lionnois, 54000 Nancy, France

${ }^{c}$ Luxembourg Institute of Science and Technology LIST, 4 avenue des hauts fourneaux-L-4362 Esch sur Alzette, Luxembourg

${ }^{\mathrm{d}}$ Institute François-Alphonse Forel and Institute for Environmental Sciences, University of Geneva, 66 Bd CarlVogt, CH-1211 Genève, Switzerland

${ }^{\text {e }}$ SLU Institutionen for vatten och mijlo Lennart Hjelms väg 9, Uppsala, SE 750 07, Sweden

Twelve supplementary figures and three supplementary tables

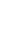


968 Figure S1: Experimental plan for Cr speciation experiments with Ion Chromatography ICP-MS (IC969 ICP-MS)

970 Table S1: Summary of the IC-ICP-MS parameters and conditions used in Cr speciation experiments

971 Figure S2: Temporal evolution of two $\mathrm{Cr}^{\mathrm{III}}$ initial concentrations (total dissolved) in ISO8692 medium 972 over $72 \mathrm{~h}$

973 Figure S3: Temporal evolution of nine $\mathrm{Cr}^{\mathrm{III}}$ initial concentrations (total dissolved) in ISO8692 medium 974 over $72 \mathrm{~h}$

975 Figure S4: Temporal evolution of nine $\mathrm{Cr}^{\mathrm{III}}$ initial concentrations (total) in ISO8692 medium over $72 \mathrm{~h}$

976 Table S2: Measured Cr concentration at $\mathrm{t}=0$ in standard (ISO 8692) medium amended with different

977 initial concentrations with and without filtration

978 Figure S5: Temporal evolution of $\mathrm{Cr}^{\mathrm{VI}}$ concentrations $\left(\mathrm{CE}_{50}\right.$ as added initial concentration) with and 979 without filtration in biotic (presence of algae) ISO medium.

980 Figure S6: Chromatograms of standard ISO 8692 biotic (presence of algae) medium amended with $981 \mathrm{Cr}^{\mathrm{VI}}$ or with $\mathrm{Cr}^{\mathrm{III}}$ at different times between 0 and $72 \mathrm{~h}$

982 Figure S7: Particle size distribution and number of particles determined with Single Particles Counter 983 in ISO algal test medium with and without addition of $\mathrm{Cr}^{\mathrm{III}}$ at different incubation times

984 Figure S8: Particle size distribution and number of particles determined with Nanoparticle Tracking 985 Analysis in ISO algal test medium with and without addition of $\mathrm{Cr}^{\mathrm{III}}$ at different incubation times

986 Figure S9: Nanoparticle Tracking Analysis results profiles before and after measurement parameters 987 modification.

988 Figure S10: Temporal evolution of chromium concentrations with and without filtration in ISO 989 medium amended with $\mathrm{Cr}^{\mathrm{III}}$ during 72 hours.

990 Table S3: Conditions and ICP-MS parameters for spICP-MS analysis.

991 Figure S11: Temporal evolution of particle number and \% of total mass occurring as particle mass or 992 Number average and mass average particle diameter.

993 Figure S12: Time-dependent changes in the distribution of the corresponding spherical diameter. 


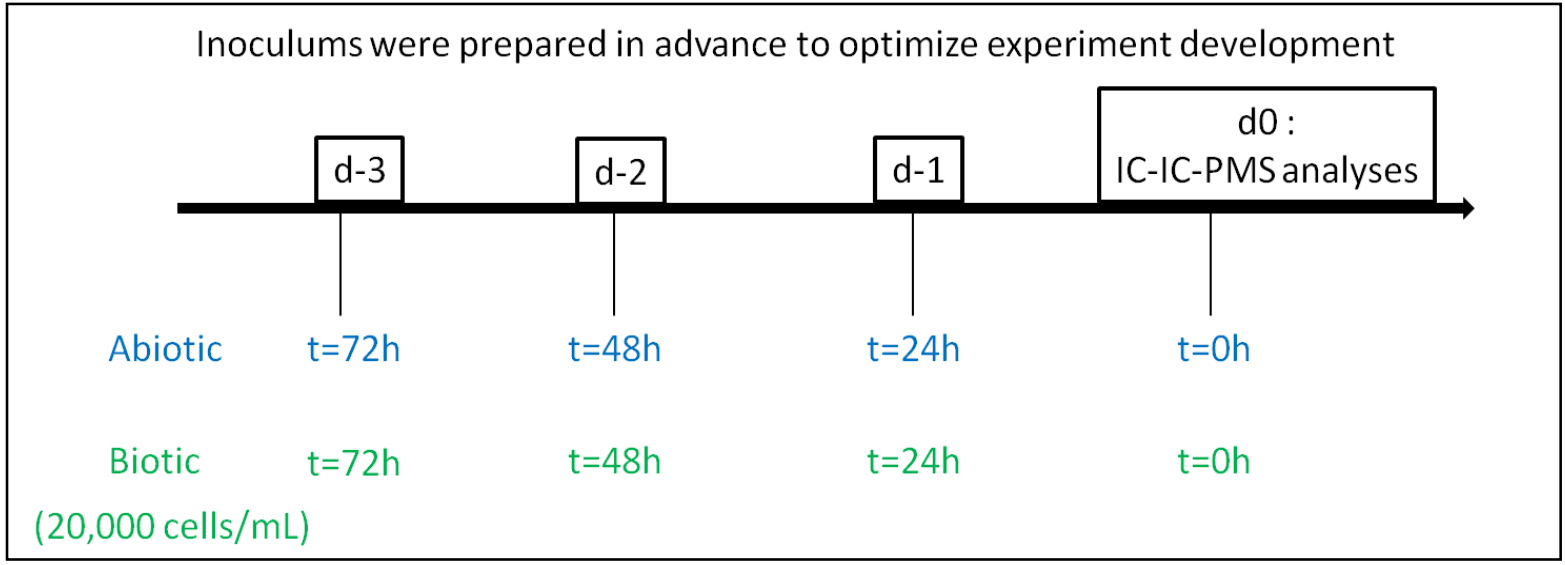

997 Figure S1. Experimental plan for speciation experiments with Ion Chromatography ICP-MS (IC-ICP998 MS). Abiotic (absence of algae) and biotic (presence of algae) samples were prepared in advance or 999 immediately prior to analysis (d0). All samples were analyzed on day 0 to optimize the analyses 1000 course in day 0.

Table S1: Summary of the IC-ICP-MS parameters and conditions used in Cr speciation experiments

\begin{tabular}{|l|l|}
\hline IC conditions & \\
\hline pump & Thermo ICS $5000+$ \\
separation column & Dionex Thermo AG7 $2 \times 50 \mathrm{~mm}$ \\
column temperature & $20{ }^{\circ} \mathrm{C}$ \\
flow rate & $0.4 \mathrm{~mol} / \mathrm{L} \mathrm{HNO}$ spiked with $1 \mu \mathrm{g} / \mathrm{L}$ of $\mathrm{Rh}$, isocratic system \\
sample volume & $500 \mu \mathrm{L} / \mathrm{min}$ \\
flushing volume & $200 \mu \mathrm{L}$ \\
duration & $1,500 \mu \mathrm{L}$ \\
\hline ICP-MS parameters & $10 \mathrm{~min}$ \\
\hline ICP-MS & \\
nebulizer & Thermo XII series \\
gas flow & $\mathrm{PFA}-\mathrm{LC}$ \\
plasma power & $0.87 \mathrm{~L} / \mathrm{min}$ \\
plasma gas flow & $1,500 \mathrm{~W}$ \\
auxiliary gas flow & $13.5 \mathrm{~L} / \mathrm{min}$ \\
detector mode & $0.77 \mathrm{~L} / \mathrm{min}$ \\
KED & pulse counting \\
CCT - KED flow rate & $\mathrm{He} / \mathrm{H}_{2}$ \\
\hline Data acquisition & $3.5 \mathrm{~mL} / \mathrm{min}-3 \mathrm{~V}$ \\
\hline ions (m/z) & \\
measurement unit & $52 \mathrm{Cr},{ }^{53} \mathrm{Cr},{ }^{103} \mathrm{Rh}$ \\
sweps/reading & counts \\
replicates & 1 \\
dwell time & 1 \\
integration time & $100 \mathrm{~ms}$ \\
\hline
\end{tabular}



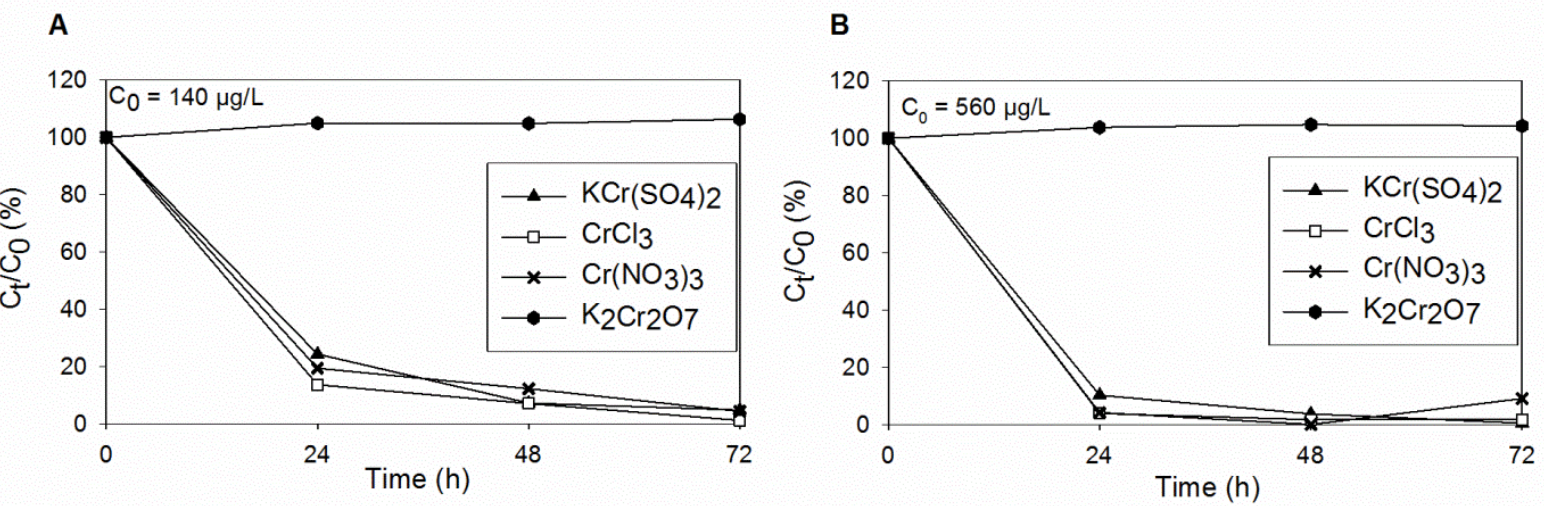

1002

1003

Figure S2. Temporal evolution (expressed as a percentage of the value measured at $t=0$ ) of total dissolved $\mathrm{Cr}$ concentrations (filtered at $0.22 \mu \mathrm{m}$ ) in standard (ISO8692) medium amended with $\mathrm{Cr}^{\text {III }}$ $\left(\mathrm{CrCl}_{3} \cdot 6 \mathrm{H}_{2} \mathrm{O}\right.$ (square) or $\mathrm{Cr}\left(\mathrm{NO}_{3}\right)_{3} \cdot 9 \mathrm{H}_{2} \mathrm{O}$ (cross) or $\mathrm{KCr}\left(\mathrm{SO}_{4}\right)_{2} \cdot 12 \mathrm{H}_{2} \mathrm{O}$ (triangle)) or $\mathrm{Cr}^{\mathrm{VI}}\left(\mathrm{K}_{2} \mathrm{Cr}_{2} \mathrm{O}_{7}\right.$ (circle)) during 72 hours. Initial concentration of each salt was $140 \mu \mathrm{g} / \mathrm{L}$ (A) or $560 \mu \mathrm{g} / \mathrm{L}$ (B).

1007

1008

1009

1010

1011

1012

1013

1014

1015

1016

1017

1018

1019

1020

1021

1022 


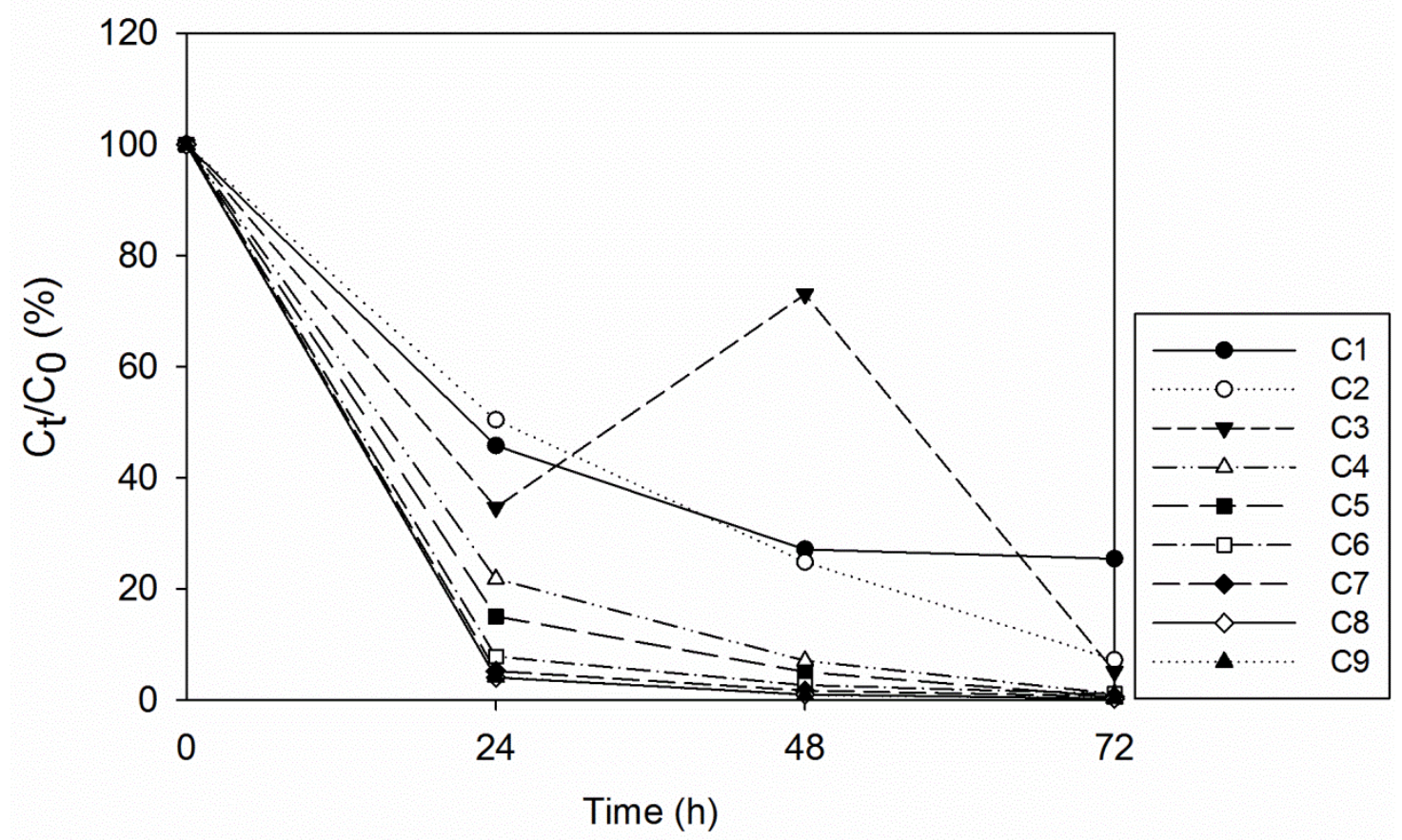

Figure S3. Temporal evolution (expressed as a percentage of the value measured at $t=0$ ) of total dissolved $\mathrm{Cr}$ concentrations (filtered at $0.22 \mu \mathrm{m}$ ) in standard (ISO 8692) medium amended with initial total concentrations of $\mathrm{CrCl}_{3} \cdot 6 \mathrm{H}_{2} \mathrm{O}$ between 20 (C1) and 7000 (C9) $\mu \mathrm{g} / \mathrm{L}$ (see Table $\mathrm{S} 2$ for the full compilation of the measured values at $\mathrm{t}=0$ ). Measurements were done in triplicate for $\mathrm{C} 1, \mathrm{C} 2, \mathrm{C} 4$ and C9 after 0 and $48 \mathrm{~h}$ of incubation. The relative standard deviations (RSD) for these measurements were usually below $10 \%$ except for $\mathrm{C} 1$ at $48 \mathrm{~h}(\mathrm{RSD}=70 \%)$ and $\mathrm{C} 2$ at $48 \mathrm{~h}(\mathrm{RSD}=40 \%)$ and $\mathrm{C} 3$ at $48 \mathrm{~h}(\mathrm{RSD}=20 \%)$. The high RSD were obtained for analytical concentrations close to the instrumental quantification limit for FAAS. Also note that, with increasing concentrations, total dissolved Cr levels were lower than the corresponding total ones already at $\mathrm{t}=0$ (see Table S2). 


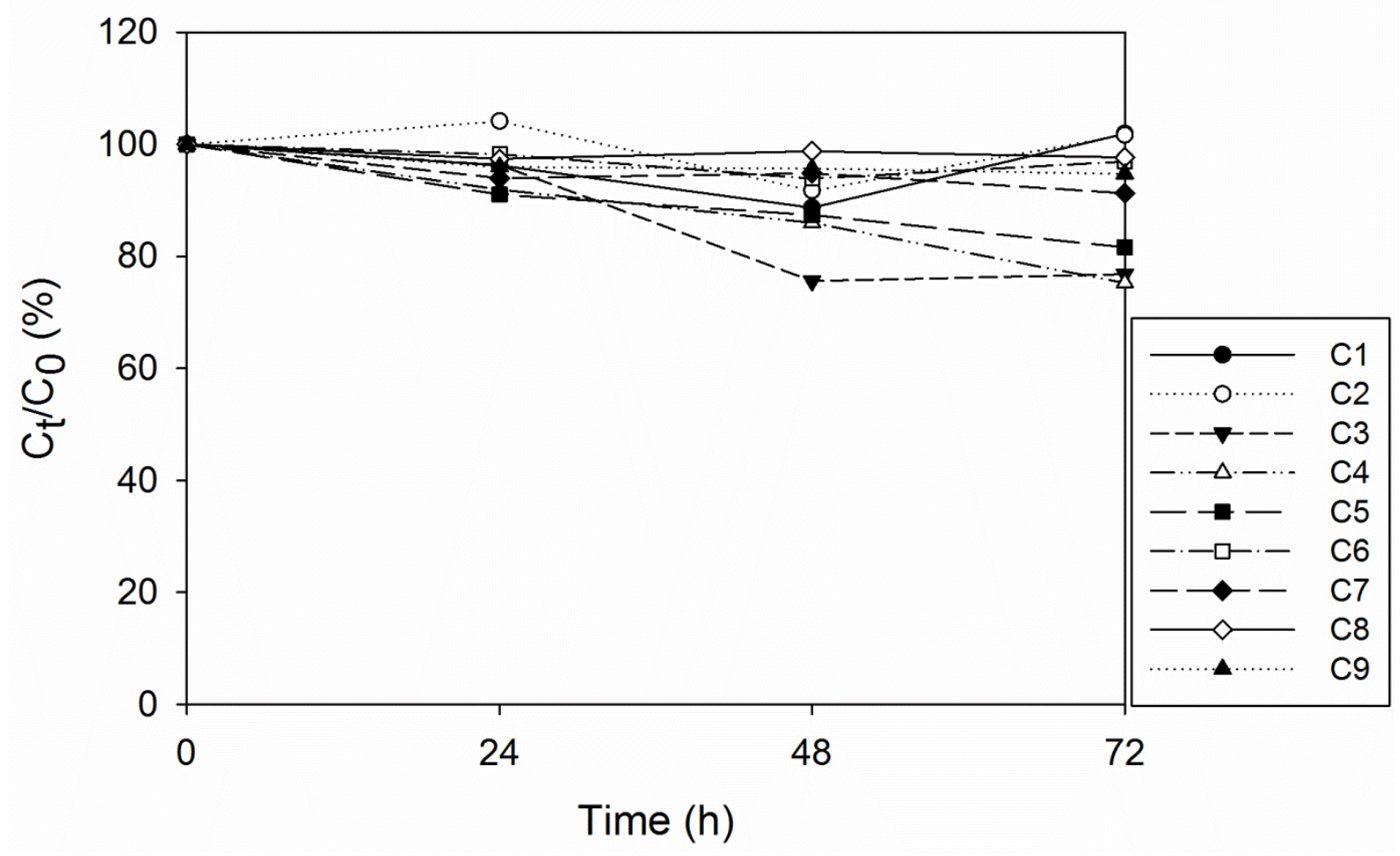

Figure S4. Temporal evolution (expressed as a percentage of the value measured at $\mathrm{t}=0$ ) of total $\mathrm{Cr}$ concentrations in standard (ISO 8692) medium amended with initial concentrations of $\mathrm{CrCl}_{3} \cdot 6 \mathrm{H}_{2} \mathrm{O}$ between 20 (C1) and 7000 (C9) $\mu \mathrm{g} / \mathrm{L}$ (see Table S2 for the full compilation of the measured values at $\mathrm{t}$ $=0$ ). Measurements were done in triplicate for $\mathrm{C} 1, \mathrm{C} 2, \mathrm{C} 4$ and $\mathrm{C} 9$ after 0 and $48 \mathrm{~h}$ of incubation. The relative standard deviations (RSD) for these measurements were usually below $10 \%$ except for $\mathrm{C} 1$ at $48 \mathrm{~h}(\mathrm{RSD}=20 \%)$ and $\mathrm{C} 2$ at $48 \mathrm{~h}(\mathrm{RSD}=15 \%)$.

Table S2. Measured Cr concentration at $\mathrm{t}=0$ in standard (ISO 8692) medium amended with different initial concentrations $(\mathrm{C} 1-\mathrm{C} 9)$ of $\mathrm{CrCl}_{3} \cdot 6 \mathrm{H}_{2} \mathrm{O}$ with and without filtration at $0.22 \mu \mathrm{m}$. All values are in $\mu \mathrm{g} / \mathrm{L}$ of $\mathrm{Cr}$.

\begin{tabular}{lcc}
\hline & $\begin{array}{l}\text { Measured total } \\
\text { concentration at } \mathrm{t}=0\end{array}$ & $\begin{array}{c}\text { Measured filterable }(0.22 \mu \mathrm{m}) \\
\text { concentration at } \mathrm{t}=0\end{array}$ \\
\hline $\mathrm{C} 1$ & 18 & 20 \\
$\mathrm{C} 2$ & 40 & 42 \\
$\mathrm{C} 3$ & 82 & 78 \\
$\mathrm{C} 4$ & 186 & 179 \\
$\mathrm{C} 5$ & 436 & 379 \\
$\mathrm{C} 6$ & 789 & 717 \\
$\mathrm{C} 7$ & 1745 & 1477 \\
C8 & 3596 & 2700 \\
C9 & 6877 & 5489 \\
\hline
\end{tabular}




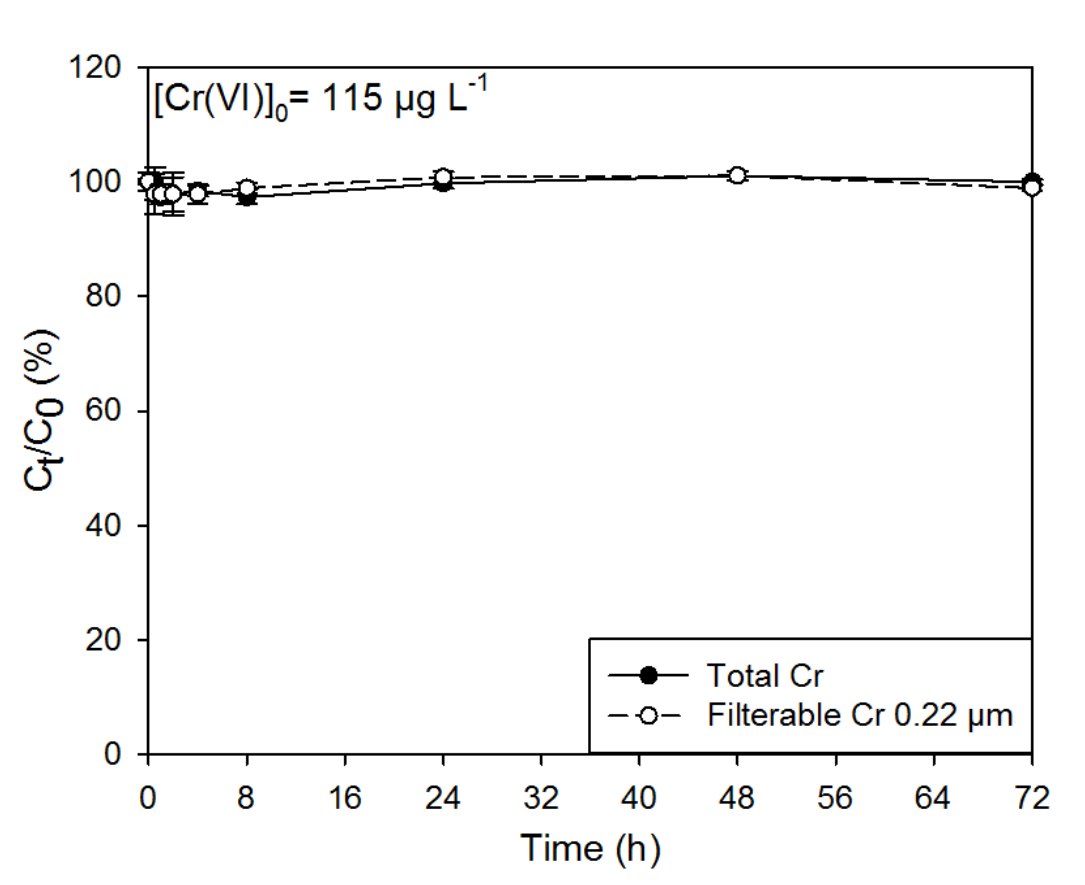

Figure S5. Temporal evolution (expressed as a percentage of the values measured at $\mathrm{t}=0$ ) of $\mathrm{Cr}$ concentrations (total $\mathrm{Cr}$ concentrations (black circles) and total dissolved $\mathrm{Cr}$ concentrations (filtered at $0.22 \mu \mathrm{m})$ (white circles) in biotic (presence of algae) ISO medium amended with $\mathrm{Cr}^{\mathrm{VI}}\left(\mathrm{K}_{2} \mathrm{Cr}_{2} \mathrm{O}_{7}\right)$ during 72 hours. Initial Cr concentration is $115 \mu \mathrm{g} / \mathrm{L}$.

1064

1065

1066

1067

1068

1069

1070

1071

1072

1073

1074

1075

1076

1077

1078

1079

1080

1081

1082 

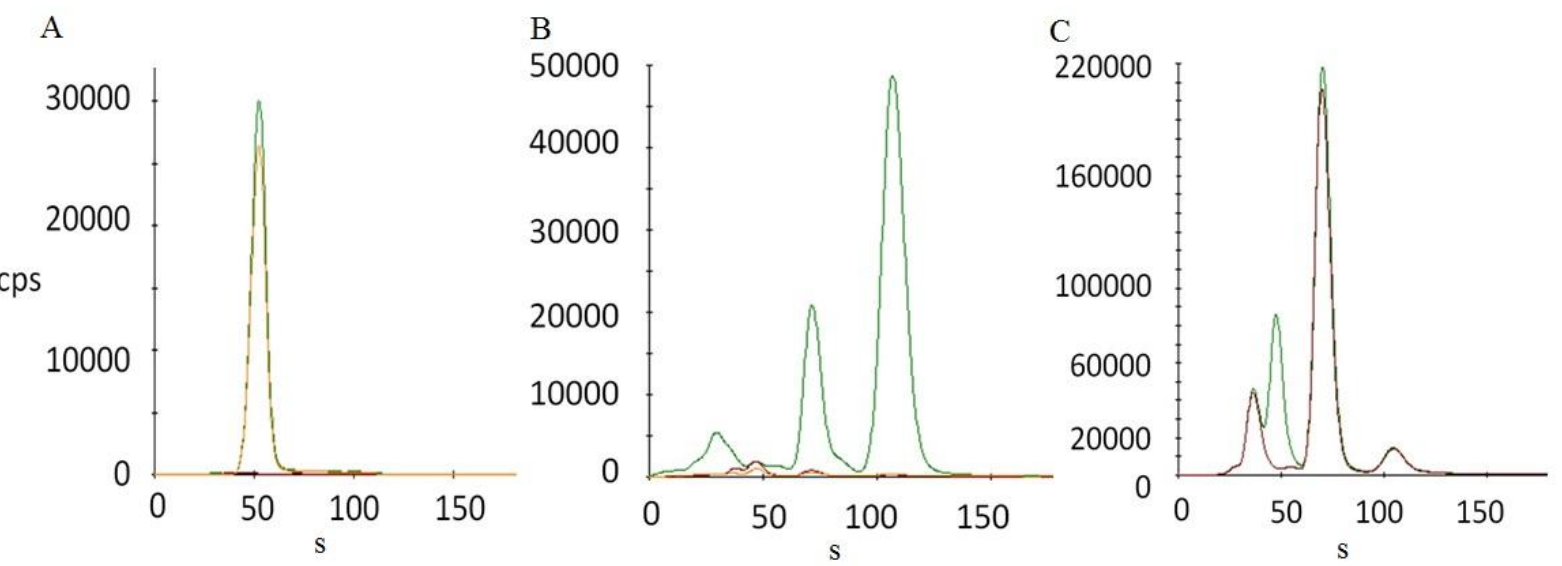

Figure S6. Chromatograms of standard ISO 8692 biotic (presence of algae, initial density 20,000 cell/ $/ \mathrm{mL}$ ) medium amended with $115 \mu \mathrm{g} / \mathrm{L}$ of $\mathrm{Cr}^{\mathrm{VI}}\left(\mathrm{K}_{2} \mathrm{Cr}_{2} \mathrm{O}_{7}\right)(\mathrm{A})$ or with $60 \mu \mathrm{g} / \mathrm{L}$ of $\mathrm{Cr}^{\mathrm{III}}\left(\mathrm{CrCl}_{3} \cdot 6 \mathrm{H}_{2} \mathrm{O}\right)$ (B) at $0 \mathrm{~h}$ (green), $24 \mathrm{~h}$ (brown), $48 \mathrm{~h}$ (orange) or $72 \mathrm{~h}$ (blue) after spiking. Chromatograms of standard ISO 8692 medium containing $60 \mu \mathrm{g} / \mathrm{L}$ of $\mathrm{Cr}^{\mathrm{III}}\left(\mathrm{CrCl}_{3} \cdot 6 \mathrm{H}_{2} \mathrm{O}\right)$ during $24 \mathrm{~h}$ (brown), and then amended with $\mathrm{Cr}^{\mathrm{VI}}\left(\mathrm{K}_{2} \mathrm{Cr}_{2} \mathrm{O}_{7}\right)$ (green) (C). All solutions were filtered $(0.22 \mu \mathrm{m})$ immediately before analysis; cps (counts per second).

1091

1092

1093

1094

1095

1096

1097

1098

1099

1100

1101

1102 


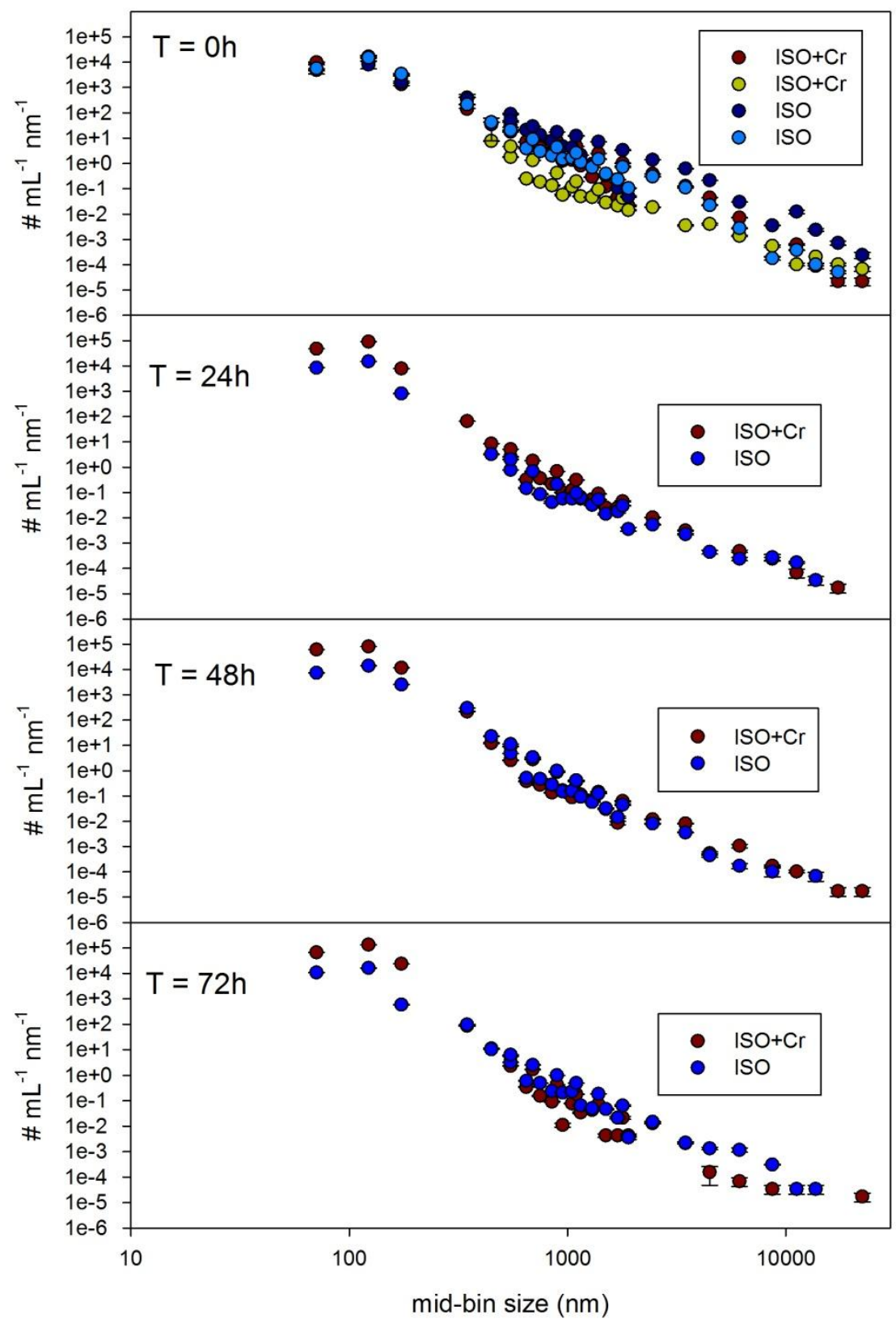

1105 Figure S7. Particle size distribution and number of particles (in $\mathrm{mL}^{-1} \mathrm{~nm}^{-1}$ ) determined with Single Particle Counter (SPC) measurements in ISO algal test medium with and without addition of $70 \mu \mathrm{g} / \mathrm{L}$ of $\mathrm{Cr}^{\mathrm{III}}$ (added as $\mathrm{CrCl}_{3} \cdot 6 \mathrm{H}_{2} \mathrm{O}$ ) at different incubation times. To obtain the number of particles per $\mathrm{mL}$ in a given size range, the values on the y-axis must be multiplied for the corresponding average size value (in $\mathrm{nm}$ ) on the $\mathrm{x}$-axis. 


\section{Optimization of operating conditions for Nanoparticle Tracking Analysis with}

\section{Nanosight NS500 instrument (Malvern instruments Ltd, UK)}

In a preliminary experiment, aliquots of test medium spiked with $0,17,35,70,140$ and 280

$\mu \mathrm{g} / \mathrm{L}$, partly covering the concentration range used in toxicity test, were analyzed by NTA. No particles were observed in aliquots spiked with $17 \mu \mathrm{g} / \mathrm{L} \mathrm{Cr}{ }^{\mathrm{III}}$ and too many particles were detected in aliquots spiked with $140 \mu \mathrm{g} / \mathrm{L}$ and $280 \mu \mathrm{g} / \mathrm{L} \mathrm{Cr}{ }^{\mathrm{III}}$. Particle concentrations in the range $1-3 \times 10^{9}$ particles $/ \mathrm{mL}$ were observed in solutions containing 35 and $70 \mu \mathrm{g} / \mathrm{L} \mathrm{Cr}{ }^{\mathrm{III}}$. The latter concentration, closed to the observed $72 \mathrm{~h} \mathrm{EC50} \mathrm{for} \mathrm{Cr}^{\mathrm{III}}$, was chosen for detailed analysis after 1, 15, 30, 45, 60, 90 and $120 \mathrm{~min}$, and 24, 48 and $72 \mathrm{~h}$ of incubation.

No particles were detected in the ultrapure water (MQW) used to prepare the test medium. Particle concentration in the blank sample (freshly prepared ISO medium) was low $(0.14 \pm$ $0.07 \times 10^{8}$ particles $/ \mathrm{mL}$ ) and particle size distribution (PSD) covered a large spectrum between 0 and $900 \mathrm{~nm}$ (Figure S9). In ISO medium spiked with $\mathrm{Cr}^{\mathrm{III}}$ and regardless of the incubation time, particle concentrations ranged between $7.85 \times 10^{8}$ and $27.5 \times 10^{8}$ particles $/ \mathrm{mL}$ with relative standard deviations (RSD) between 6 and $59 \%$ (Figure S8 and S9). Particles detected by NTA had a mean size between 100 and $135 \mathrm{~nm}$ with RSD between $1 \%$ and $12 \%$ (Figure S9). The high RSD of some particle concentration measurements were caused by the systematic decrease in particle number between the first and the third replicate measurement (Figure S9 A, B and C). The total (unfiltered) Cr concentration was stable over $72 \mathrm{~h}$ and ranged between $62 \mu \mathrm{g} / \mathrm{L}$ at $\mathrm{t}=0$ and $66 \mu \mathrm{g} / \mathrm{L} 72 \mathrm{~h}$ after spiking. However, the total filterable $\mathrm{Cr}$ concentration decreased over time from $60 \mu \mathrm{g} / \mathrm{L}$ at $\mathrm{t}=0$ to $16 \mu \mathrm{g} / \mathrm{L}$ after $72 \mathrm{~h}$ (Figure $\mathrm{S} 10$ ). Examination of the videos recorded during NTA showed that the number of particles visible in the field of the camera was stable during data acquisition for the first replicate, but increased with time for replicates two and three. 
1137 Measurement parameters were modified by adding a waiting step of $60 \mathrm{~s}$ before data

1138 acquisition for replicates two and three and RSD on particle concentrations was reduced to 1-

$1139 \quad 11 \%$ (Figure S9 D, E and F).

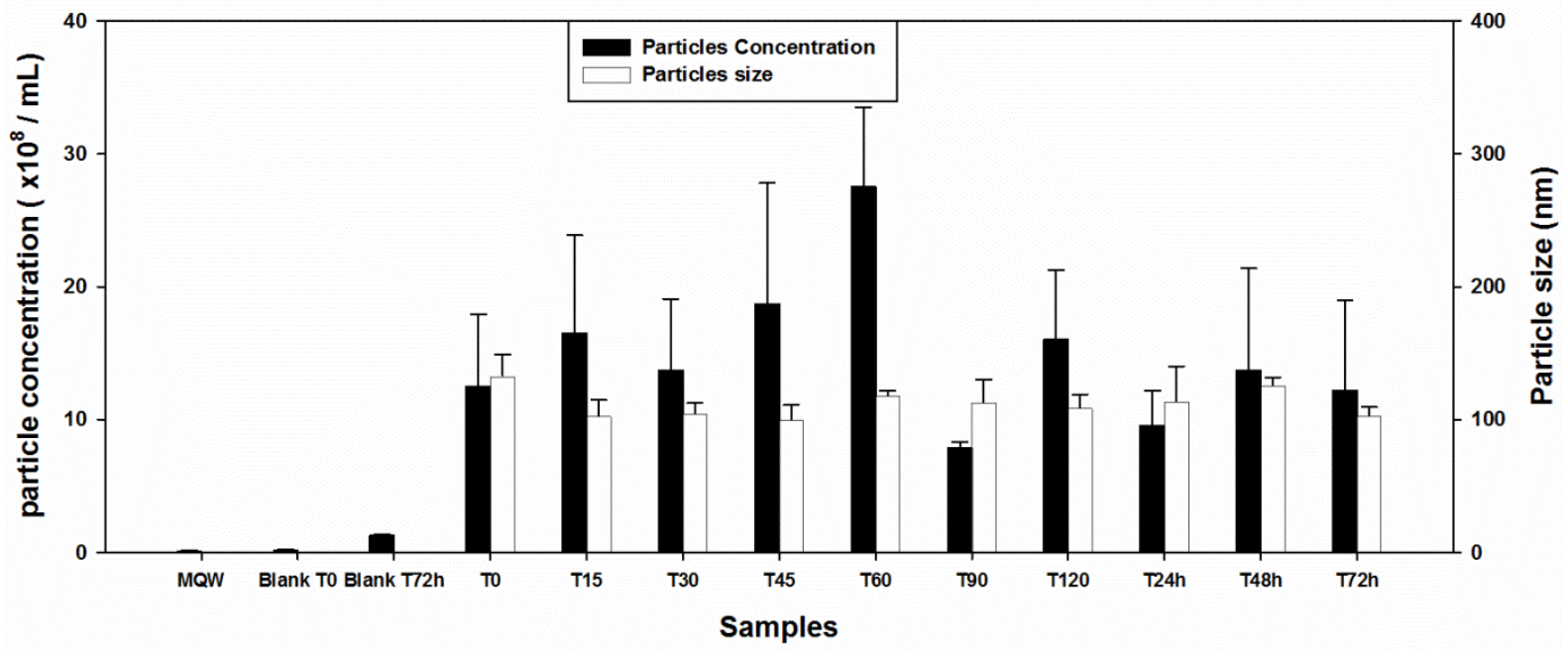

Figure S8. Particle concentration (black bars) and size (white bars) measured by nanoparticles tracking

1142 analysis (NTA) in standard (ISO 8692) medium spiked or not with $70 \mu \mathrm{g} / \mathrm{L}$ of $\mathrm{CrCl}_{3} \cdot 6 \mathrm{H}_{2} \mathrm{O}$ for 1143 different incubation time between 0 and $120 \mathrm{~min}$ and after 24, 48 and $72 \mathrm{~h}$. 


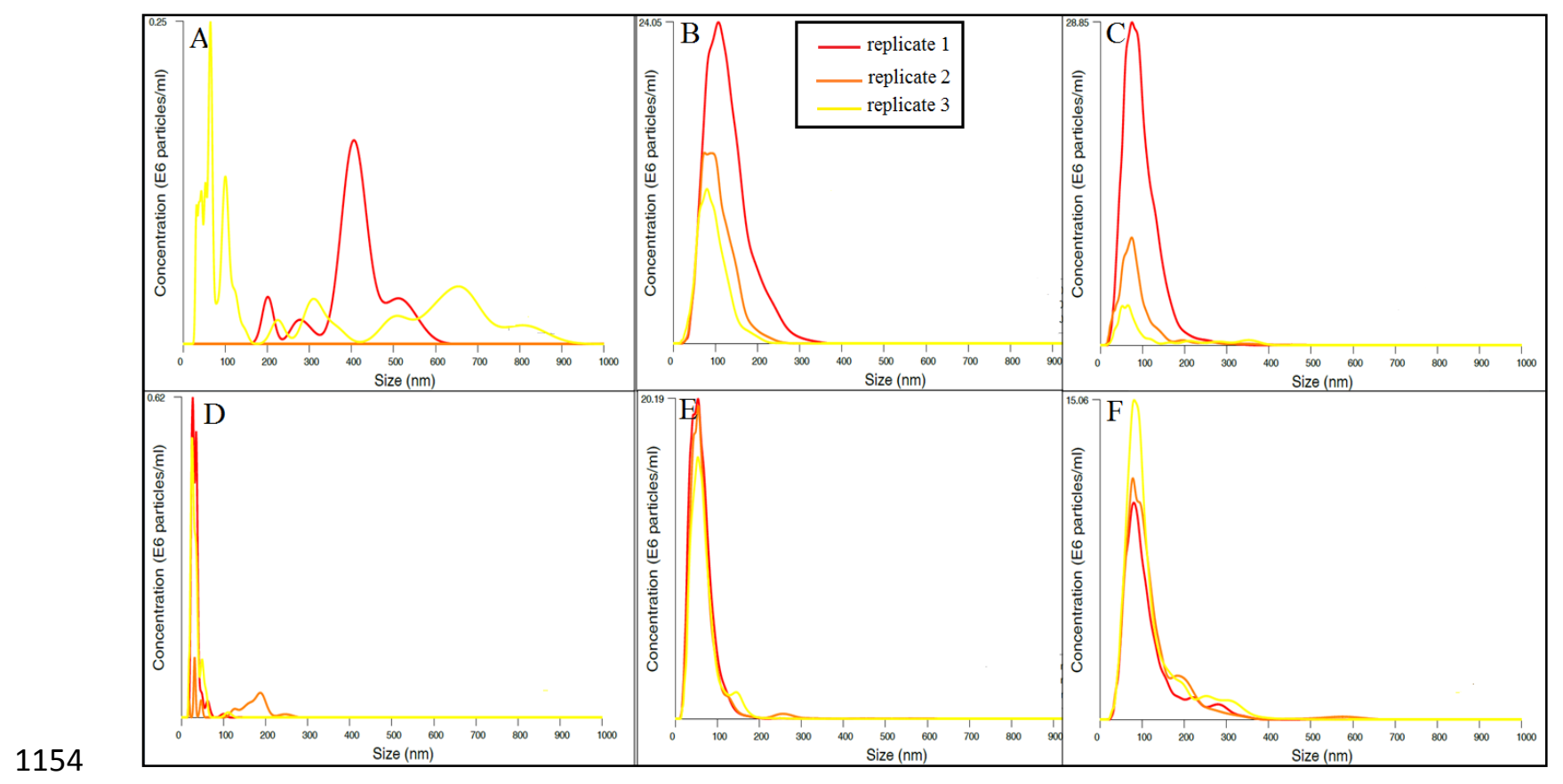

1155 Figure S9. Comparison of reproducibility of results profiles before (A, B and C) and after (D, E and F) 1156 measurement parameters modification by adding a waiting step of $60 \mathrm{~s}$ before data acquisition for 1157 replicates 2 and 3. This edit to the experimental procedure aimed to harmonize the waiting time before 1158 each replicate measurement; i.e. to increase the waiting time for replicates two and three from 5 1159 seconds to $60 \mathrm{~s}$. This experiment was realized in ISO test medium spiked with $60 \mu \mathrm{g} / \mathrm{L} \mathrm{of} \mathrm{Cr}^{\mathrm{III}}$, 1160 corresponding to the previously determined EC50 at $72 \mathrm{~h}$

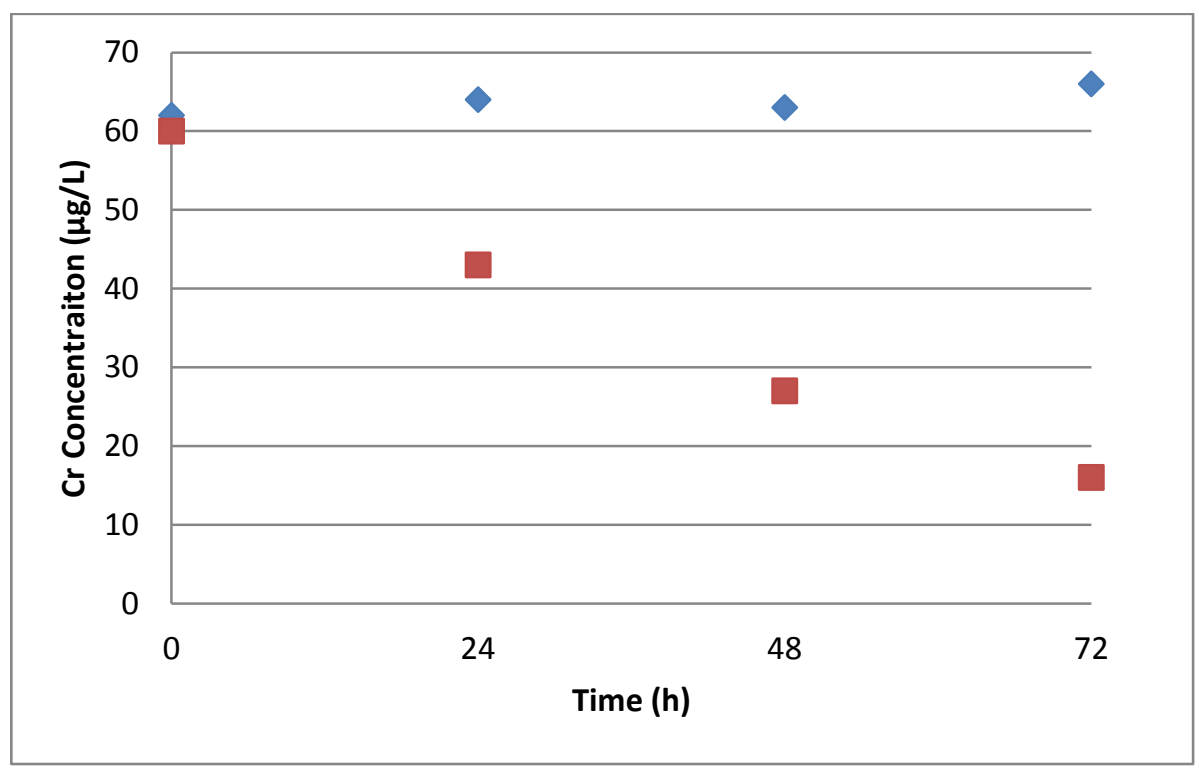

1163 Figure S10. Temporal evolution of $\mathrm{Cr}$ concentrations in $\mu \mathrm{g} / \mathrm{L}$ (total $\mathrm{Cr}$ concentrations (blue squares), 1164 and filterable $\mathrm{Cr}$ concentrations $(0.22 \mu \mathrm{m})$ (red squares) in ISO medium amended with $\mathrm{Cr}^{\mathrm{III}}$ $\left(\mathrm{CrCl}_{3} \cdot 6 \mathrm{H}_{2} \mathrm{O}\right)$ during 72 hours. Initial nominal $\mathrm{Cr}$ concentration is $70 \mu \mathrm{g} / \mathrm{L}$. 


\section{Corresponding spherical size and number concentration determination using single} particle ICP-MS (spICP-MS) analysis using the Nexion $350 \mathrm{D}$

When nanoparticles arrive in the ICP-MS plasma they are turned into ions thus forming a cloud of ions. Truly dissolved ions are homogeneously distributed in solution and when injected into the plasma thus cause a continuous, yet fluctuating, stream of ions to be detected by the detector. Nanoparticles can thus be distinguished from dissolved ions as the former cause intensive peaks in the detected time dependent signal, each time a cloud of ions from a nanoparticle arrives at the detector. The intensity of this peak can be calculated into some measure of size, provided that a composition and shape are assumed for the particles (Table $\mathrm{S} 3)$. Only one isotope $\left({ }^{52} \mathrm{Cr}\right)$ was measured simultaneously, whereas any $\mathrm{Cr}$-containing particles formed because of hydrolysis most likely also contained oxygen atoms and protons.

No collision cell gas was used to remove ${ }^{40} \mathrm{Ar}^{12} \mathrm{C}$ interferences on the ${ }^{52} \mathrm{Cr}$ signal. Hence, a continuous background signal was recorded, not consisting of ${ }^{52} \mathrm{Cr}$ but of the ${ }^{40} \mathrm{Ar}^{12} \mathrm{C}$ interference. However, by using short dwell times, the intensity of any background signal reduces proportionally more than the short but intense nanoparticle signals [1]. It was thus hypothesized that better size detection limits could be obtained by using a relatively small dwell time, but still measuring in standard mode, where the sensitivity towards the most abundant $\mathrm{Cr}$ isotope $\left({ }^{52} \mathrm{Cr}\right)$ is highest. The used dwell time of $50 \mu$ s and the absence of settling time cause nanoparticle events to be spread over multiple subsequent measurement events that need to be integrated separately for each event. Moreover, distinguishing non-dissolved from dissolved signals was needed, because interferences still caused a relatively high background signal. Both requirements were achieved using a previously published method [2]. This method calculates an intensity cut-off value based on a number of times the standard deviation of the background signal. Integrated peak surfaces below this cut-off value are considered to stem from dissolved events and are not taken into account when recalculating 
1191 the average signal and the standard deviation of the background signal. The method converges

1192 when no new particle events are identified and the particle size distribution is then calculated 1193 from the particle events intensities. Such a single cut-off value is known to lead to both false 1194 positives (peaks mistakenly considered particle events) and false negatives (peaks mistakenly 1195 considered dissolved events) [3]. The goal of the spICP-MS measurement was to verify the 1196 hypothesis of the presence of Cr-containing particles in the samples. Hence, a high and thus 1197 conservative number of standard deviations (5) was used to minimize false positives, rather 1198 than to minimize false negatives [4].

1199 The calculations were realized with a software called Nanocount, which is freely available at 1200 http://blogg.slu.se/Nanocount. 
1211 Table S3: Conditions and ICP-MS parameters for spICP-MS analysis

\begin{tabular}{|l|l|}
\hline ICP-MS parameters & \\
\hline ICP-MS & Nexion 350D \\
nebulizer & GE Micromist \\
gas flow & $0.87 \mathrm{~L} / \mathrm{min}$ \\
plasma power & $1,500 \mathrm{~W}$ \\
plasma gas flow & $13.5 \mathrm{~L} / \mathrm{min}$ \\
auxiliary gas flow & $0.77 \mathrm{~L} / \mathrm{min}$ \\
detector mode & pulse counting \\
KED & Standard \\
\hline Data acquisition & \\
\hline ions (m/z) & $52 \mathrm{Cr}$ \\
measurement unit & counts \\
sweeps/reading & $10^{6}$ \\
replicates & 1 \\
dwell time & $0.05 \mathrm{~ms}$ \\
integration time & $50,000 \mathrm{~ms}$ \\
\hline Data treatment & \\
\hline Integration method & Fixed window \\
Peak integration time & $20 \mathrm{~ms}$ \\
Minimum cluster size & 4 ions \\
Signal discrimination method & Outlier analysis \\
Number of standard deviations & 5 \\
for cut-off calculation & 5 \\
Assumed composition & Cr(OH) 3 \\
Assumed density & $3.11 \mathrm{~g} \mathrm{~cm}{ }^{-3}$ \\
Assumed shape & sphere \\
\hline
\end{tabular}



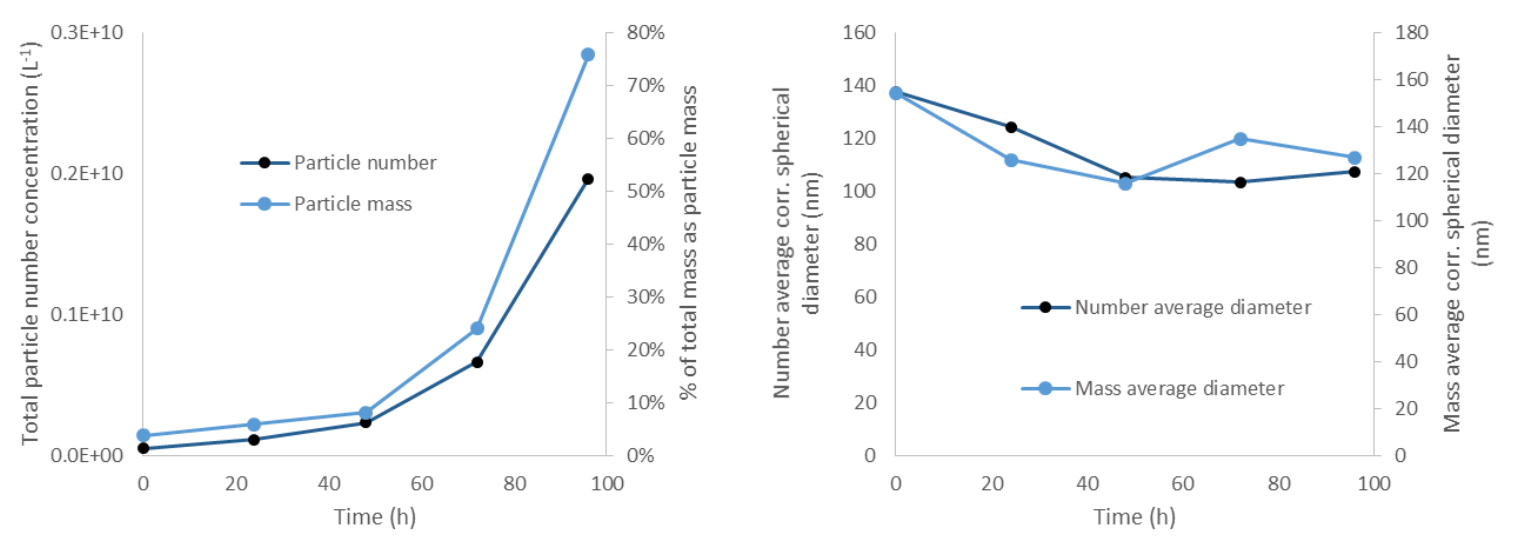

Figure S11. Temporal evolution of particle number and \% of total mass occurring as particle mass 1221 (left) or number average and mass average particle diameter (right). The diameters are corresponding 1222 spherical diameters calculated using the setting in Table S3.

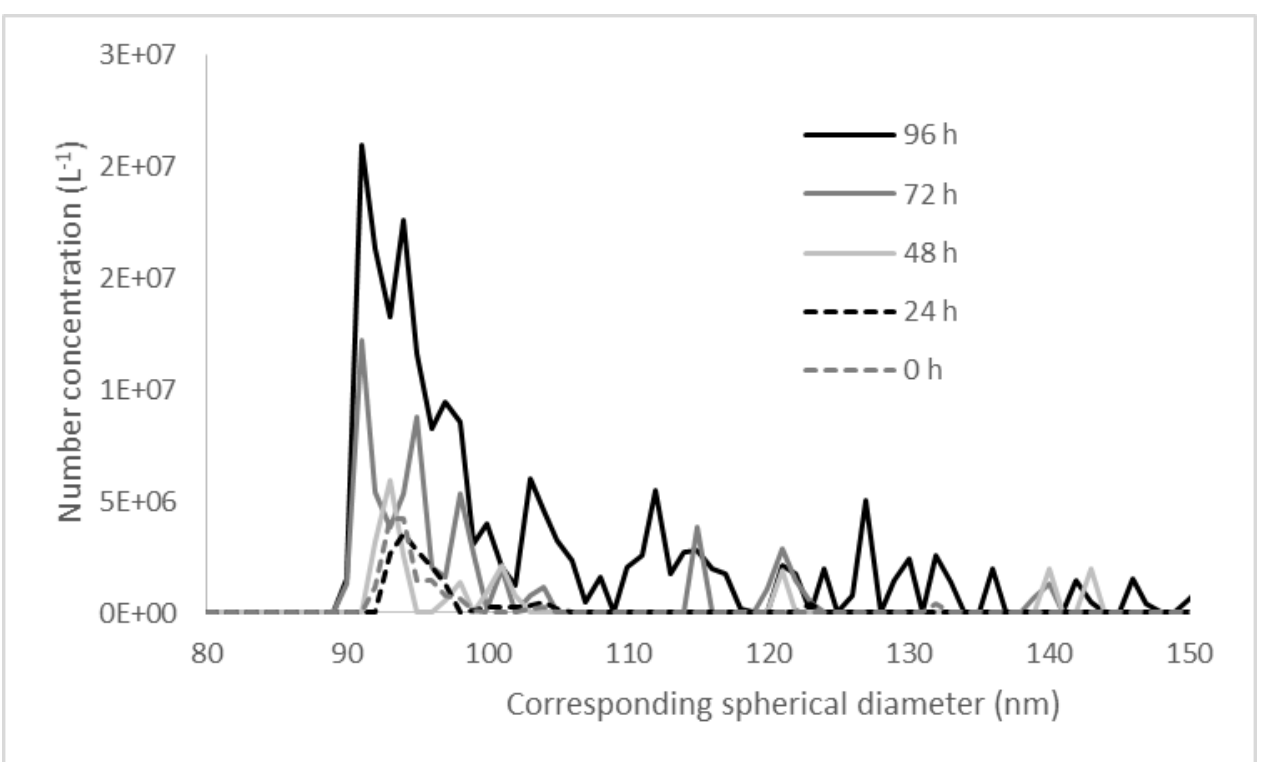

Figure S12. Temporal evolution in the distribution of the corresponding spherical diameter. The diameters are corresponding to spherical diameters calculated using the setting in Table S3. 
1235 (1) Montaño MD, Badiei HR, Bazargan S, Ranville JF.2014. Improvements in the detection and 1236 characterization of engineered nanoparticles using spICP-MS with microsecond dwell times. Environ. 1237 Sci. Nano. 1(4): 338-346.

1238 (2) Tuoriniemi J, Cornelis G, Hassellöv MA.2015. new peak recognition algorithm for detection 1239 of ultra-small nano-particles by single particle ICP-MS using rapid time resolved data acquisition on a 1240 sector-field mass spectrometer. J. Anal. At. Spectrom. 30 (8): 1723-1729.

1241 (3) Cornelis G, Hassellöv MA.2013. signal deconvolution method to discriminate smaller 1242 nanoparticles in single particle ICP-MS. J. Anal. At. Spectrom. 29 (1): 134-144.

1243 (4) Tuoriniemi J, Cornelis G, Hassellöv M. 2012. Size Discrimination and Detection Capabilities 1244 of Single-Particle ICPMS for Environmental Analysis of Silver Nanoparticles. Anal. Chem. 84 (9): $1245 \quad 3965-3972$. 